Seattle University School of Law

Seattle University School of Law Digital Commons

5-8-2015

\title{
Washington's War on the Visibly Poor: A Survey of Criminalizing Ordinances \& Their Enforcement
}

Justin Olson

Scott MacDonald

Sara Rankin

Seattle University School of Law

Follow this and additional works at: https://digitalcommons.law.seattleu.edu/hrap

\section{Recommended Citation}

Olson, Justin; MacDonald, Scott; and Rankin, Sara, "Washington's War on the Visibly Poor: A Survey of Criminalizing Ordinances \& Their Enforcement" (2015). Homeless Rights Advocacy Project. 9.

https://digitalcommons.law.seattleu.edu/hrap/9

This Article is brought to you for free and open access by the Law School Archives at Seattle University School of Law Digital Commons. It has been accepted for inclusion in Homeless Rights Advocacy Project by an authorized administrator of Seattle University School of Law Digital Commons. 


\section{WASHINGTON'S WAR ON THE VISIBLY POOR:}

\section{A Survey of Criminalizing Ordinances \& Their Enforcement}

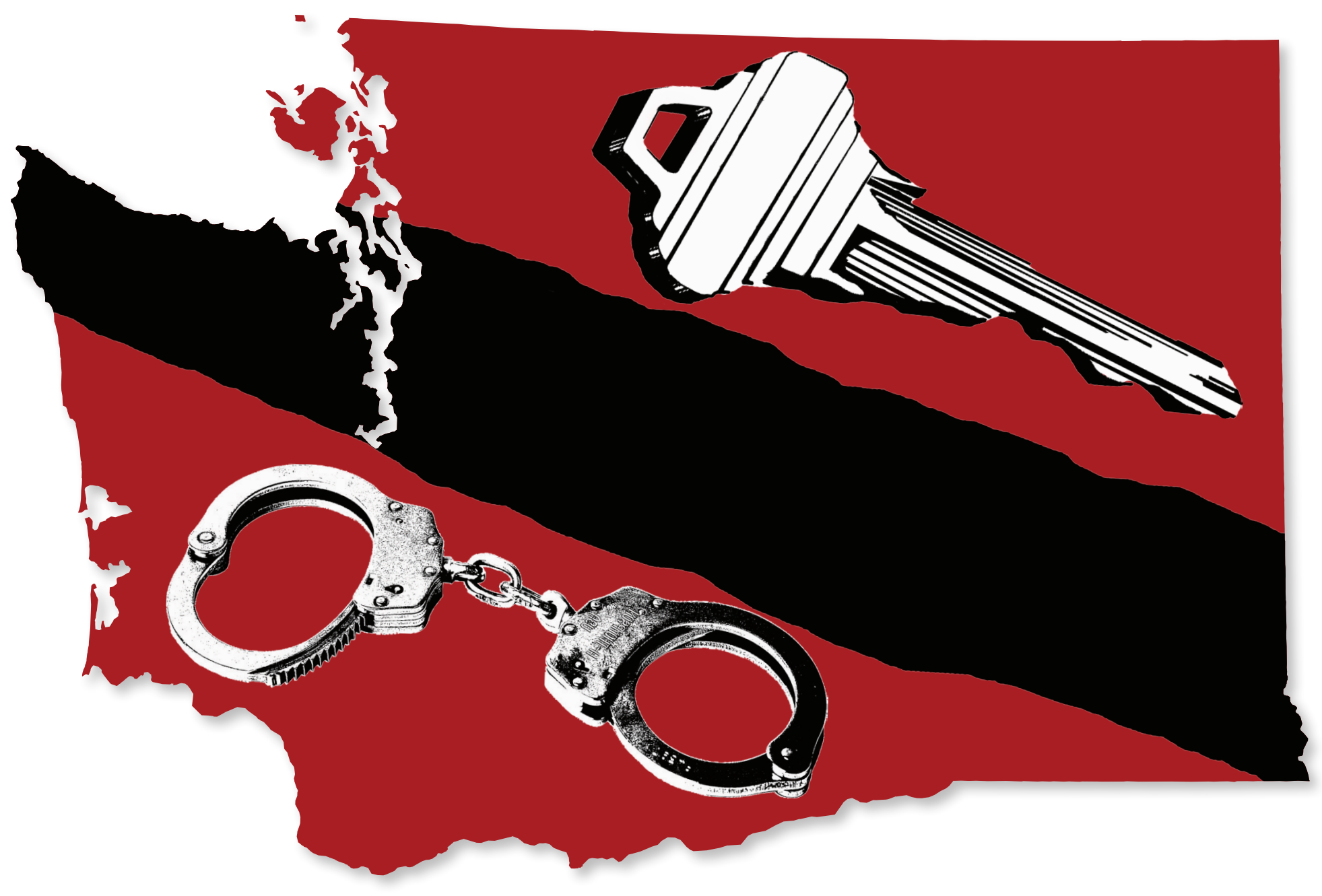

SEATTLE

U N I V E RS I T Y

SCHOOL OF LAW

HOMELESS RIGHTS

ADVOCACY PROJECT 


\title{
Washington's War on the Visibly Poor:
}

\section{A Survey of Criminalizing Ordinances \& Their Enforcement}

\author{
AUTHORS \\ Justin Olson \& Scott MacDonald \\ EDITOR \\ Sara K. Rankin
}




\section{ACKNOWLEDGMENTS}

The Homeless Rights Advocacy Practicum is a section of the Homeless Rights Advocacy Project (HRAP) at Seattle University School of Law's Korematsu Center. Scott MacDonald and Justin Olson, law students at Seattle University School of Law and founding members of HRAP, authored this policy brief under the supervision of Professor Sara Rankin of Seattle University School of Law. The authors are deeply grateful to the following individuals for their time and contributions toward the preparation of this brief:

- Paul Boden, Executive Director (Western Regional Advocacy Project)

- The Honorable Bill Bowman (King County Superior Court)

- Mark Davidson, Member (Williams Kastner, PLLC)

- David Harrison, Partner (Miller \& Harrison, LLC)

- The Seattle University School of Law Criminal Justice Research Methodology students led by Professor Matthew J. Hickman

- The Honorable Judith Hightower (Seattle Municipal Court)

- Carla Lee, Deputy Chief of Staff (King County Prosecuting Attorney's Office)

- Chris Lee, Local Artist

- Nick Licata, Councilmember (City of Seattle)

- Officer Daniel McCormack, Homeless Outreach Team (Colorado Springs Police Department)

- Our HRAP colleagues Kaya Lurie, Josh Howard, Javier Ortiz, Matthew Dick, Breanne Schuster, and David Tran

- Mark Solomon, Crime Prevention Coordinator (Seattle Police Department)

- Nancy Talner, Staff Attorney (American Civil Liberties Union)

- Michelle Thomas, Director of Policy and Advocacy (Washington Low Income Housing Alliance)

- The University of California, Berkeley School of Law Policy Advocacy Clinic, including students Marina Fisher, Nathaniel Miller, and Lindsay Walter, along with Clinic Director Jeffrey Selbin

- Alex West, Policy and Advocacy Session Aide (Washington Low Income Housing Alliance)

And finally, but perhaps most emphatically, the authors would like to thank Professor Sara Rankin, whose passion for homeless rights advocacy inspired and guided us through every phase of this daunting process. 


\section{TABLE OF CONTENTS}

EXECUTIVE SUMMARY

INTRODUCTION

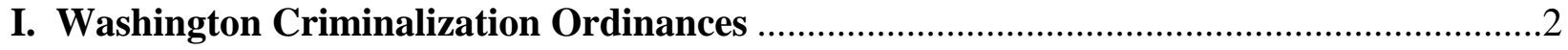

A. Not In Our State: Increasing Statewide Commitment to Criminalization ............................2

B. Not On Our Streets: The Focus of Criminalization ……….............................................

C. Not In Our City: Municipalities with the Most Criminalization..........................................6

D. Legal and Policy Concerns: Overlapping and Compound Ordinances ...............................7

1. Overlapping Ordinance …………………………...........................................

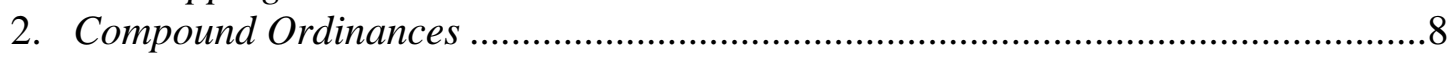

3. Prevalence in Municipalities ………………………........................................8

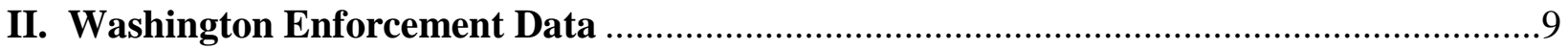

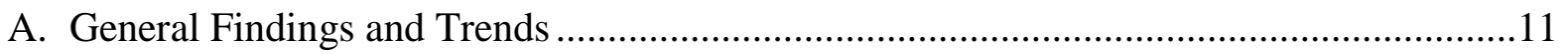

1. Predicting Enforcement: The Effects of Income Disparity ....................................11

2. Comparing Local Enforcement to National Trends ...........................................12

3. Civil vs. Criminal: To Jail or Not To Jail .............................................................12

B. Under the Microscope: A Case Study of Seven Cities ....................................................14

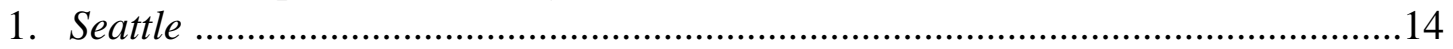

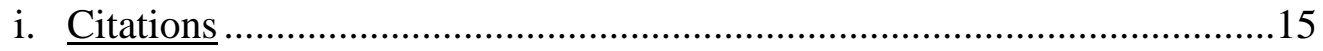

ii. Case Dispositions ....................................................................................

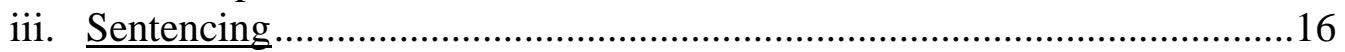

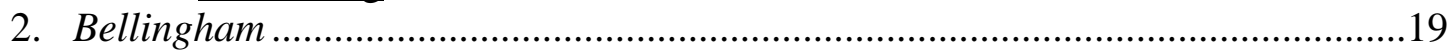

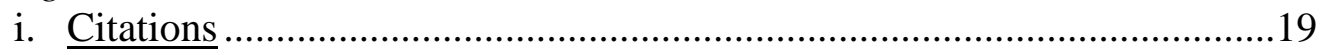

ii. Case Dispositions and Sentencing ………………..................................19

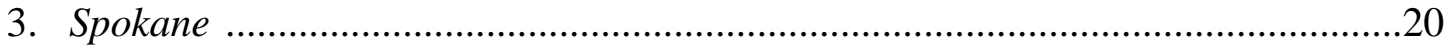

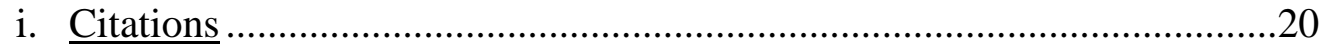

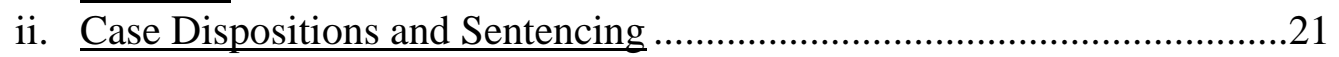

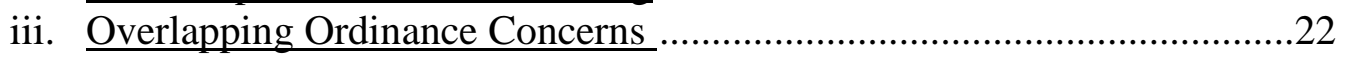

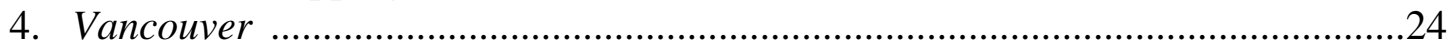

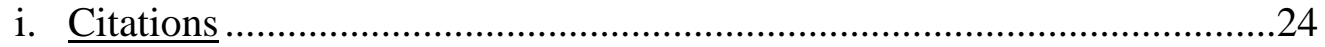

ii. Case Dispositions and Sentencing ………………..................................24

iii. Overlapping Ordinance Concerns .............................................................25

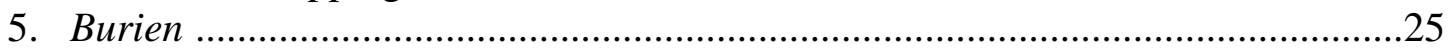

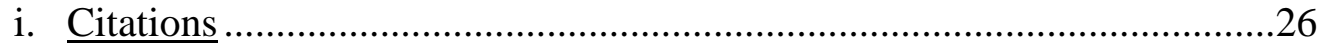

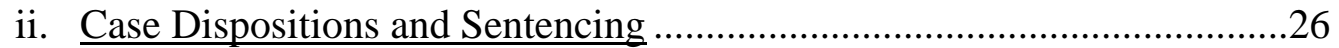

iii. Overlapping Ordinance Concerns ..............................................................2

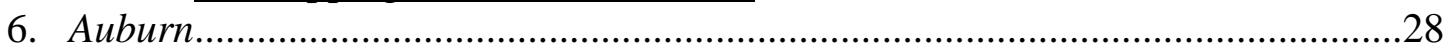

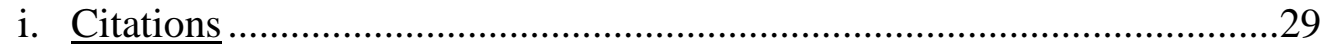

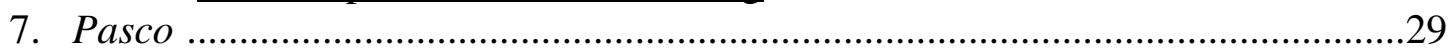




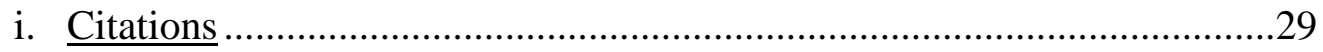

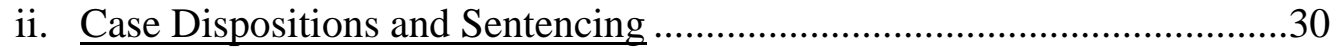

iii. Overlapping Ordinance Concerns .......................................................30

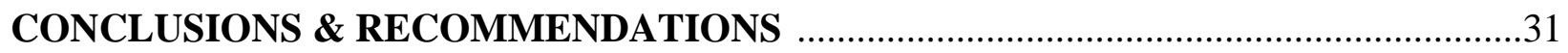

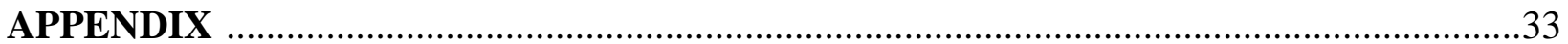




\section{EXECUTIVE SUMMARY}

Throughout the country, there are laws punishing behaviors that are necessary for survival. For those without shelter, there is no alternative but to conduct these behaviors in public. Camping outdoors, urinating in public, sitting or lying down on sidewalks - these laws target homeless people either in practice or outright. But until now, no one knew how widespread these laws are throughout Washington, or how they are being enforced. This brief answers these questions.

HRAP researchers surveyed the municipal codes of 72 cities across Washington to identify ordinances that essentially criminalize homelessness in each jurisdiction. From this survey, researchers created a chart tracking every ordinance they could find. Seven of the cities were selected as case studies for closer examination of the enforcement and citations of these ordinances. The findings reveal that homeless criminalization exists regardless of where you live. From densely populated urban cities to scattered rural townships, city councils are increasingly passing these laws, often drafting them in a way that raises serious legal and policy concerns about how Washington treats its most vulnerable residents.

This brief shines a spotlight on the problems with these laws: how they are written, how they impact the homeless community, and how easily cities can fall into the trap of vilifying already vulnerable populations in the name of safety and public health. This report shows that the problem of criminalizing homelessness, so often buried in municipal codes, is both widespread and systemic. Key findings of the brief include:

Washington cities increasingly criminalize homelessness by outlawing necessary, lifesustaining activities:

- Laws that prohibit or limit sitting or standing in public places $(78 \%$ of surveyed municipalities)

- Laws that prohibit or limit sleeping in public places $(78 \%)$

- Although the majority of cities in Washington (75\%) criminalize urination and defecation in public, cities typically fail to provide sufficient access to reasonable alternatives such as 24-hour restrooms and hygiene centers

Whether you live in a small town or a large metropolis, municipalities are likely to aggressively criminalize homelessness:

- Since 2000, Washington cities have enacted new ordinances targeting homelessness in 288 new ways, increasing the amount of criminalization by more than $50 \%$ compared to prior years

- As population rises, the minimum number of criminalization laws also rises

- At least two-thirds (66\%) of cities draft criminalization ordinances in a way that either overlap with other ordinances or contain compound provisions that criminalize multiple, and often unrelated, behaviors; these practices create legal and policy concerns

- Auburn is the city with the highest number of criminalization ordinances (14 ordinances/population 70,000), followed by Spokane (12), Pasco (12), Everett (11), and Bellingham (11) 
- Auburn also criminalizes the broadest range of surveyed activities (13 categories), followed Spokane (12), Puyallup (12), University Place (12), and Pasco (11)

- Seattle has the highest total population $(609,000)$ but was in the median range of criminalization ordinances (7)

Enforcement of criminalization ordinances raises both legal and policy concerns, such as inconsistent or selective citation and sentencing practices:

- As rates of income disparity rise, so does the rate of citations issued for purported violations of criminalization ordinances

- Monetary penalties varied between civil infraction fees of $\$ 250$ or more up to misdemeanor charges as high as $\$ 5,000$

- Civil infractions can evolve into criminal violations or otherwise result in criminality for homeless defendants; for example, in the likely event that a homeless defendant "fails to respond" or "fails to pay" the fee for the civil infraction

- In 2013, 87\% of defendants sentenced to jail time under Seattle's Pedestrian Interference ordinance spent more than 30 days in jail, compared to $42 \%$ in 2009

- Seattle cited individuals for "camping in public" at a disproportionately higher rate compared to other ordinances within its jurisdiction (4,117 citations or $71 \%)$

- More warrants were issued for standing, sitting, or sleeping in public places than for any other categories of behavior

- In addition, custody times revealed a high number of individuals spending more than 90 days in jail for violating criminalization ordinances, especially in Seattle (38)

Although a comprehensive list of policy recommendations is beyond the scope of this report, HRAP researchers can make the following key recommendations to Washington policymakers:

- Local lawmakers should abandon the policy of imposing sanctions for the conduct of necessary, life-sustaining activity because people experiencing homelessness have no reasonable alternatives but to survive in public

- Civil infractions should never result in criminal penalties if the defendant is unable to pay or whose housing status makes an appearance or payment highly unlikely

- Jurisdictions should stop the practice of writing overlapping and compound ordinances that raise legal and policy concerns

- Policymakers should re-examine and reject laws that discriminatorily impact visibly poor people 


\section{INTRODUCTION}

Homelessness leads to a variety of daily hurdles: finding a safe place to sleep, securing shelter from the elements, and obtaining necessary sustenance, to name only a few. Increasingly, cities make overcoming these hurdles more difficult. Cities criminalize "visible poverty" by literally criminalizing evidence of it. Visible poverty refers to the real or perceived state of being poor in public spaces, and social science proves what we intuitively know to be true: bearing witness to visible poverty creates discomfort in passersby. ${ }^{1}$ The policy of criminalizing homelessness has been described as "a social control mechanism used to make the blighted human circumstances disappear instead of getting at the root of the concern and addressing it in a meaningful way." " In fact, the trend of passing criminalization ordinances on a local level is neither new nor effective ${ }^{3}$ at addressing the core problems associated with homelessness-for the homeless individual or for the community at large. ${ }^{4}$ Other studies provide compelling data on the increasing criminalization of homelessness; ${ }^{5}$ however, to date, no entity has performed a Washington-specific analysis. This brief seeks to remedy that deficit.

Between 2014 and 2015, members of the Seattle University School of Law Homeless Rights Advocacy Project ("HRAP") conducted a survey of 72 municipalities within Washington State (representing 56\% of the state population) - the most extensive survey of its kind within the nation. ${ }^{6}$ The purpose of this study was to identify ordinances that criminalize homelessness by targeting the conduct of necessary, life-sustaining activities and disproportionately impacting homeless individuals (such as laws that prohibit sitting, sleeping, lying down, panhandling, erecting shelters in public, and more).

HRAP researchers first created a chart with links to every criminalization ordinance throughout the state. ${ }^{7}$ Upon completing the chart, researchers initiated public records requests to seven cities that enacted higher numbers of ordinances. These requests sought (1) enforcement data for the identified ordinances during a five year period from January 1, 2009, through December 31, 2013, and (2) demographic data regarding the characteristics of defendants cited

\footnotetext{
${ }^{1}$ Sara K. Rankin, A Homeless Bill of Rights (Revolution), 45 SETON HALl L. REV. 383, 390-92 (2015), available at http://ssrn.com/abstract=2376488.

${ }^{2}$ Interview with Carla Lee, Deputy Chief of Staff, King County Prosecuting Attorney's Office, SEATTLE UNIVERSITY HOMELESS RighTS ADVOCACY PROJECT (Mar. 2, 2015).

${ }^{3}$ Josh Howard \& David Tran, Seattle University Homeless Rights Advocacy Project, AT WhAT CoST: THE Minimum Cost of CRiminalizing Homelessness In SEATTLE \& SpoKane (Sara Rankin ed., 2015).

${ }^{4}$ See Javier Ortiz \& Matthew Dick, Seattle University Homeless Rights Advocacy Project, THE WRONG SIDE OF HISTORY: A COMPARISON OF MODERN \& HISTORICAL CRIMINALIZATION LAWS (Sara Rankin ed., 2015); see also Howard \& Tran, supra note 3.

${ }^{5}$ See, e.. . , THE NATIONAl LaW Center ON Homelessness \& Poverty, From Wrongs To Rights: The Case For HOMELESS BILL OF RIGHTS LEGISLATION (2014), available at http://nlchp.org/documents/Wrongs_to_Rights_HBOR [hereinafter “THE NATIONAL LAW CENTER"]; U.C. Berkeley School of Law Policy Advocacy Clinic, California's New Vagrancy Laws: The Growing Enactment and Enforcement of Anti-Homeless Laws in the Golden State (2015).

${ }^{6}$ The survey included every municipality in the 2010 United States Census with populations exceeding 5,000, covering more than $3,700,000$ people (56\% of the State's population), plus two additional cities based on geographic spread. Omak and Colville, having a population of less than 5,000, were not included in the relevant 2010 Census data but were included in this survey to provide geographic representation.

${ }^{7}$ For a full discussion of the methodologies employed by researchers, please see infra Appendix III.
} 
under these ordinances. ${ }^{8}$ Although HRAP researchers encountered several logistical limitations, they obtained a significant amount of data regarding how local cities within Washington State criminalize homeless individuals. Of course, this brief cannot capture all of the laws that may be creatively enforced against the visibly poor. There is an omnipresent need for ongoing research.

This brief is divided into four major parts. Part I reviews key findings and trends with regard to the enactment of ordinances. Part II discusses the results of the public records requests for enforcement data. Part III synthesizes and analyzes the ordinance data analysis with the enforcement data. Finally, Part IV presents recommendations for improving future efforts to collect and analyze homelessness criminalization data in other jurisdictions.

\section{WASHINGTON CRIMINALIZATION ORDINANCES}

A statewide effort to identify specific criminalization ordinances serves to detail the scope and extent of criminalization throughout the state so that advocates, businesses, service providers, city agencies, and citizens are better educated about the way the homeless are criminalized throughout Washington State. This section provides a summary of core findings regarding a given jurisdiction's propensity to criminalize visible poverty. In particular, this section summarizes: (1) the increasing enactment of criminalizing ordinances over time; (2) the most commonly criminalized behaviors across Washington State; (3) the municipalities with the highest rates of criminalization as measured by the variety of behaviors covered; and (4) the proliferation of overlapping and compound ordinances.

\section{A. Not In Our State: Increasing Statewide Commitment to Criminalization}

Criminalization is now local lawmakers' preferred method for addressing the problem of homelessness. Cities are giving themselves new ways to remove homeless people from public spaces, and are doing so at exponentially higher rates. More alarmingly, this trend has intensified in the past fifteen years.

Over half of new criminalization efforts occurred after 2000. This fourteen year span has already eclipsed the previous forty-five years' total enactment numbers, and the numbers are continuing to rise. The graph below shows the number of new avenues cities enacted to criminalize homeless conduct over five-year increments: ${ }^{9}$

\footnotetext{
${ }^{8}$ See infra Appendix I-A (enforcement data request template) and I-B (demographic data request template).

${ }^{9}$ Data based on charting the enactment year of every surveyed ordinance. The entry does not merely chart ordinance enactment, because a single ordinance might result in two new avenues of targeting homeless conduct.
} 


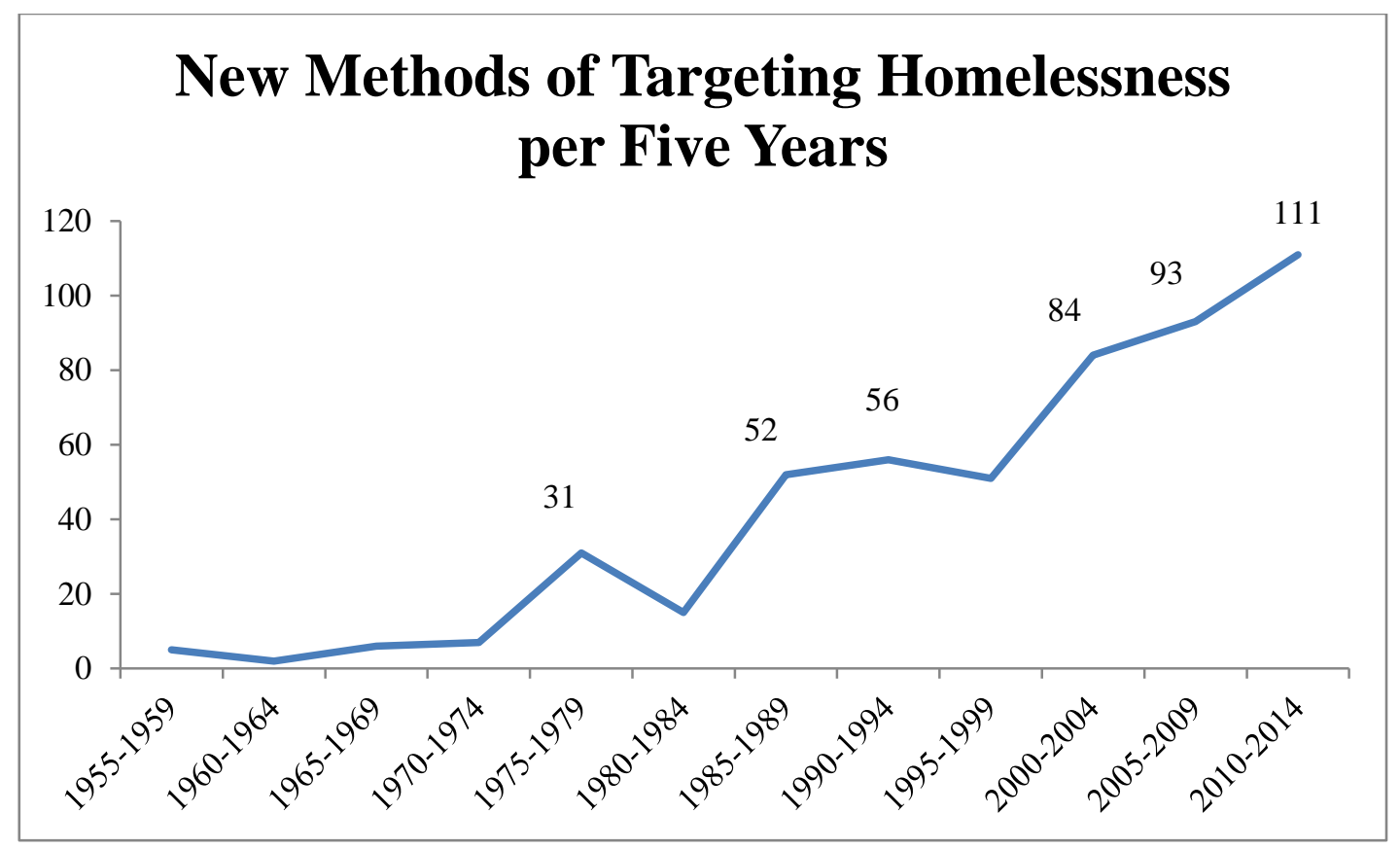

These Washington specific numbers reinforce evidence from other studies showing that lawmakers are committed to addressing the problem of homelessness through criminalization. ${ }^{10}$ However, the graph above does not depict amendments to the original ordinances, which would further reinforce that lawmakers are dedicated to criminalization even after revisiting the issue. In reality, a significant number of pre-2000 ordinances have been reaffirmed or even strengthened by post-2000 amendments.

\section{B. Not On Our Streets: The Focus of Criminalization}

It is not easy for new ordinances to come into being. Homeless criminalization ordinances are written up and proposed to city councilmembers, who then vigorously debate the benefits and drawbacks of each ordinance before voting on its passage. Sometimes, similar ordinances are discussed across the state; other times, certain types of conduct may be a concern only in particular cities, or perhaps even only in other states. In all instances, the passage of ordinances can serve as a window into the priorities of each municipality, as well as illuminate common approaches to homelessness statewide.

In Washington State, the most commonly criminalized behaviors are such benign activities as sitting or standing in public spaces $(78 \%)^{11}$ and sleeping in public spaces $(78 \%) .{ }^{12}$ Another frequently targeted behavior is urination or defecation in public (75\%). Although the majority of cities in Washington criminalize this activity, studies have shown that cities often fail to provide sufficient access to 24-hour restrooms and hygiene centers. ${ }^{13}$ The fourth most

\footnotetext{
${ }^{10}$ See The NATIONAL LAW CENTER, supra note 5; U.C. Berkeley School of Law, supra note 5.

${ }^{11}$ This category includes cities with one or more law criminalizing sitting/lying down, obstruction of sidewalks, loitering, or vagrancy.

12 This category includes cities with one or more laws that criminalize either sleeping or camping in particular public places or in public citywide.

${ }^{13}$ THE NATIONAL LAW CENTER, supra note 5.
} 
frequently prohibited activity is "aggressive" panhandling (63\%). These ordinances specifically target visibly poor people and hold them to a higher standard than existing assault or harassment laws, which often prohibit the same type of conduct but are facially neutral. The following graph demonstrates the percentage of Washington cities that prohibit each of the prohibited behaviors surveyed:

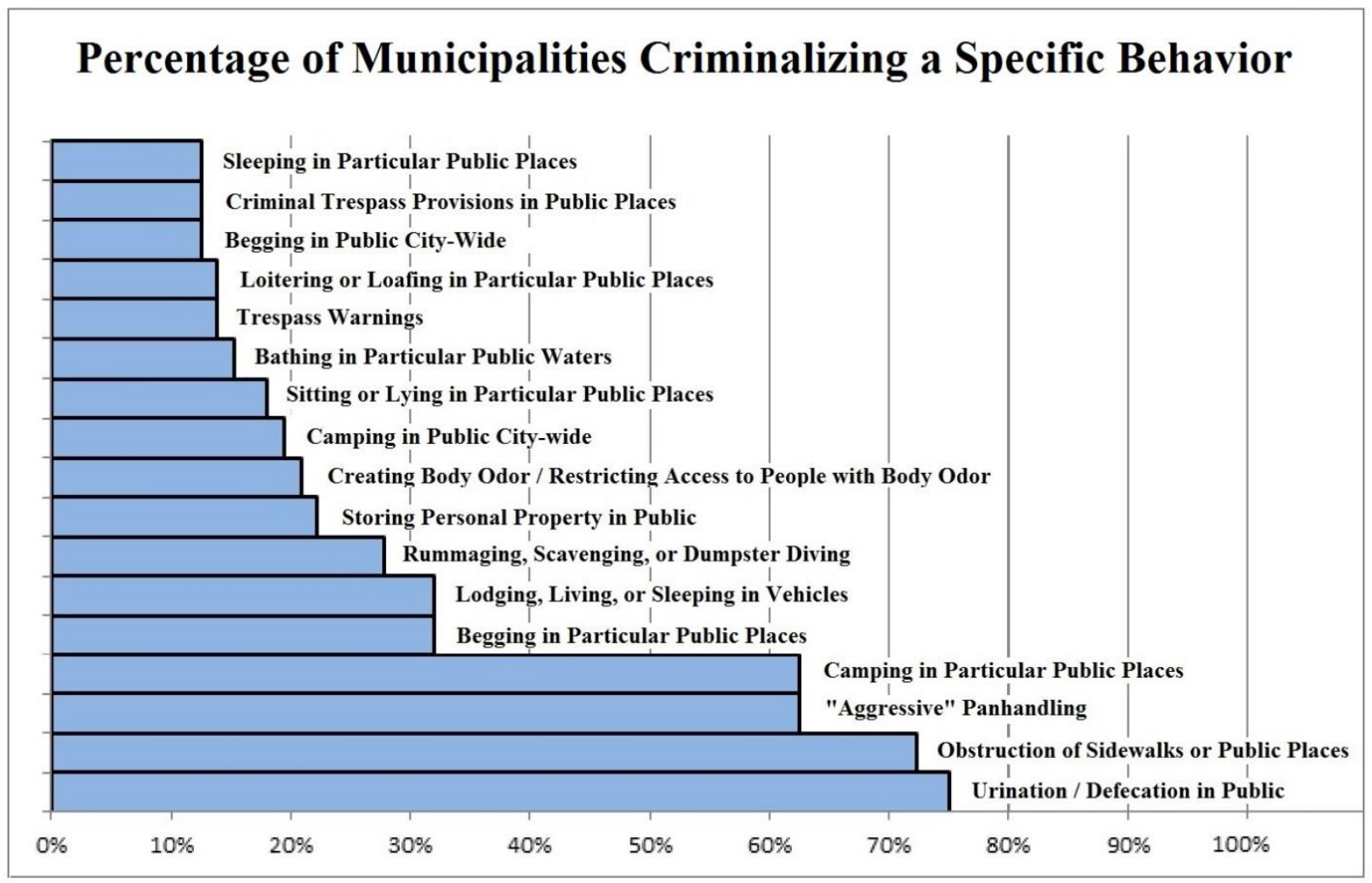

Although some ordinances may appear neutral on their face, in practice, many disproportionately target visibly poor people. For example, 20 cities (28\%) prohibit any kind of rummaging or scavenging through trash receptacles. Additionally, 16 cities (22\%) criminalize the storage of personal property in public places and 15 cities $(21 \%)$ criminalize or restrict access to public facilities to those who create body odor. Homeless individuals often have no reasonable alternatives but to violate such ordinances, and housed individuals are far less likely to become offenders.

Laws prohibiting urination and defecation in public are a prime example of the sort of practical, disparate impact on homeless individuals that results from seemingly neutral laws. Although such laws may have legitimate health and sanitation purposes, they are not written with consideration to the availability - or lack thereof — of 24-hour public restrooms and hygiene centers. Indeed, access to public restrooms for unsheltered people is sorely lacking all throughout the country. ${ }^{14}$ Looking only at Seattle, a Google search for "24-hour bathrooms" yields the following results:

${ }^{14} I d$. 


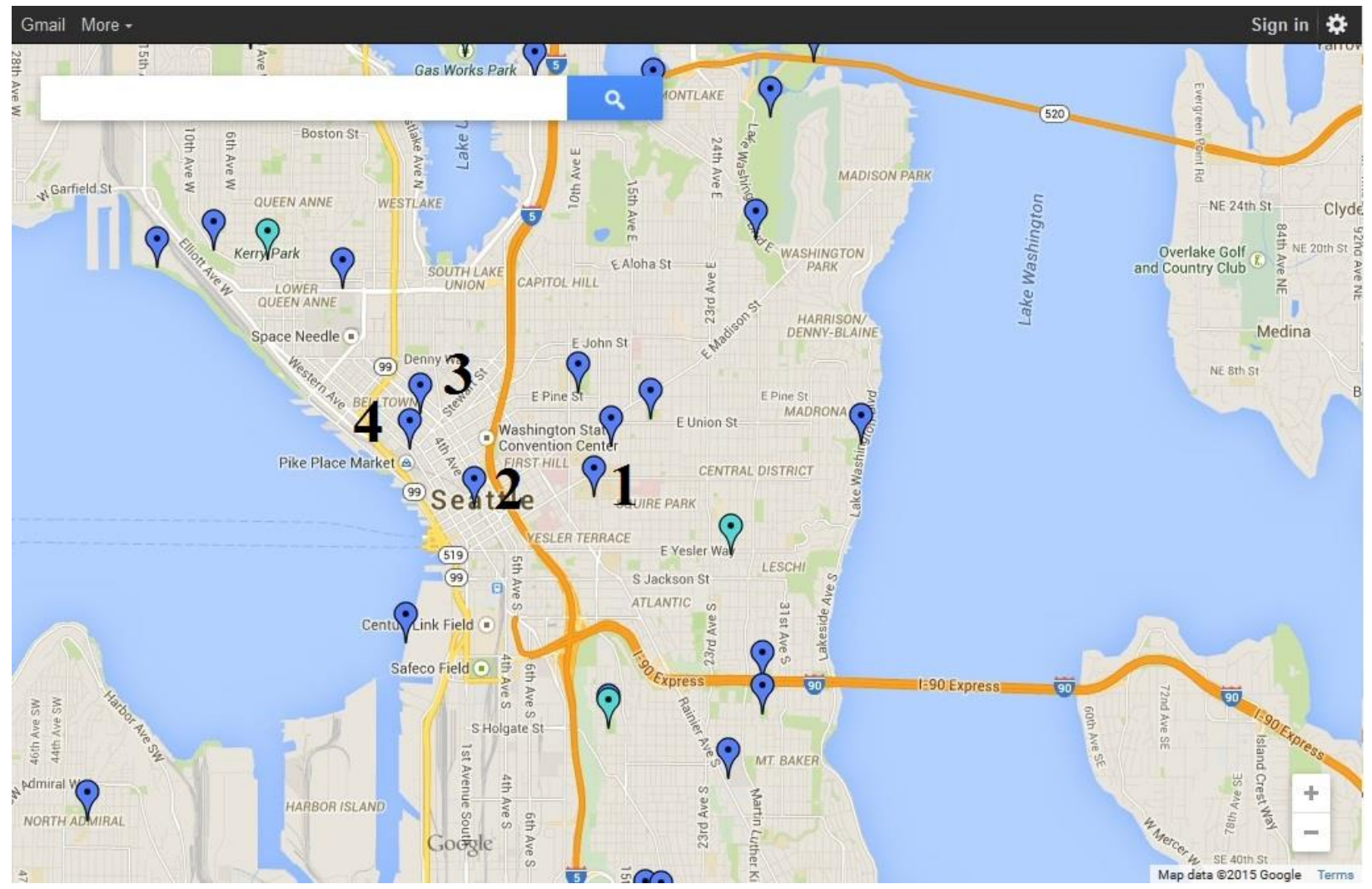

So, consider this likely scenario: if an individual living in downtown Seattle needs to use the bathroom late at night, that person might try one of the four numbered bathroom locations. However, numbers 1-3 are not always available to the public; they are for the Seattle University Park (private athletic field), the Seattle Public Library (closed in the evening), and Whole Foods Market (private business location and closed in the evening). Only number 4, the bathroom at Pike Place Market, is both open to the public and available 24-hours per day; functionally, this single location is the only option for a homeless individual in downtown Seattle. Even if an unsheltered man, woman, or child who needed to use the restroom in the middle of the night knew of these options, they would need to contend with getting there. In this way, a facially neutral law - prohibiting public urination or defecation - has a significant, practical, and disproportionate effect on those who truly have no reasonable alternatives.

Like many cities elsewhere in the nation, Washington municipalities are increasingly enacting such nuanced ordinances criminalizing behaviors that purport to fall under health, safety, or general public order. ${ }^{15}$ Given increasing criticism of such laws from a legal and policy perspective, Washington policymakers should reconsider this trend. ${ }^{16}$

\footnotetext{
${ }^{15}$ A complete chart summarizing the range of categorized behavior is available in the separately-published Washington Criminalization Ordinance Data. Scott MacDonald \& Justin Olson, Seattle University Homeless Rights Advocacy Project, WASHINGTON CRIMINALIZATION ORDINANCE DATA (Sara Rankin ed., 2015), [hereinafter referred to as ORDINANCE DATA] at Part XII. For a full discussion of municipal responses to constitutional defenses, please see Katherine Beckett and Steve Herbert's influential work. KATHERINE BECKETT \& STEVE HERBERT, BANISHED: THE NEW SOCIAL CONTROL IN URBAN AMERICA (2009).

${ }^{16}$ See Ortiz \& Dick, supra note 4.
} 


\section{Not in Our City: Municipalities with the Most Criminalization}

Homeless criminalization occurs in cities all throughout Washington. Researchers examined those cities with both the highest total number of ordinances and the greatest variety in behaviors prohibited. The resulting list reflects cities with no apparent commonalities. As a result, homeless individuals have no ability to predict safe harbors in Washington.

Auburn criminalizes 13 behaviors, the most of any surveyed city in Washington. Spokane, Puyallup, and University Place each criminalize 12 different behaviors. Pasco, Arlington, and Vancouver all criminalized 11 behaviors. ${ }^{17}$ The graph below provides a visual representation of how many cities criminalize a given number of activities.

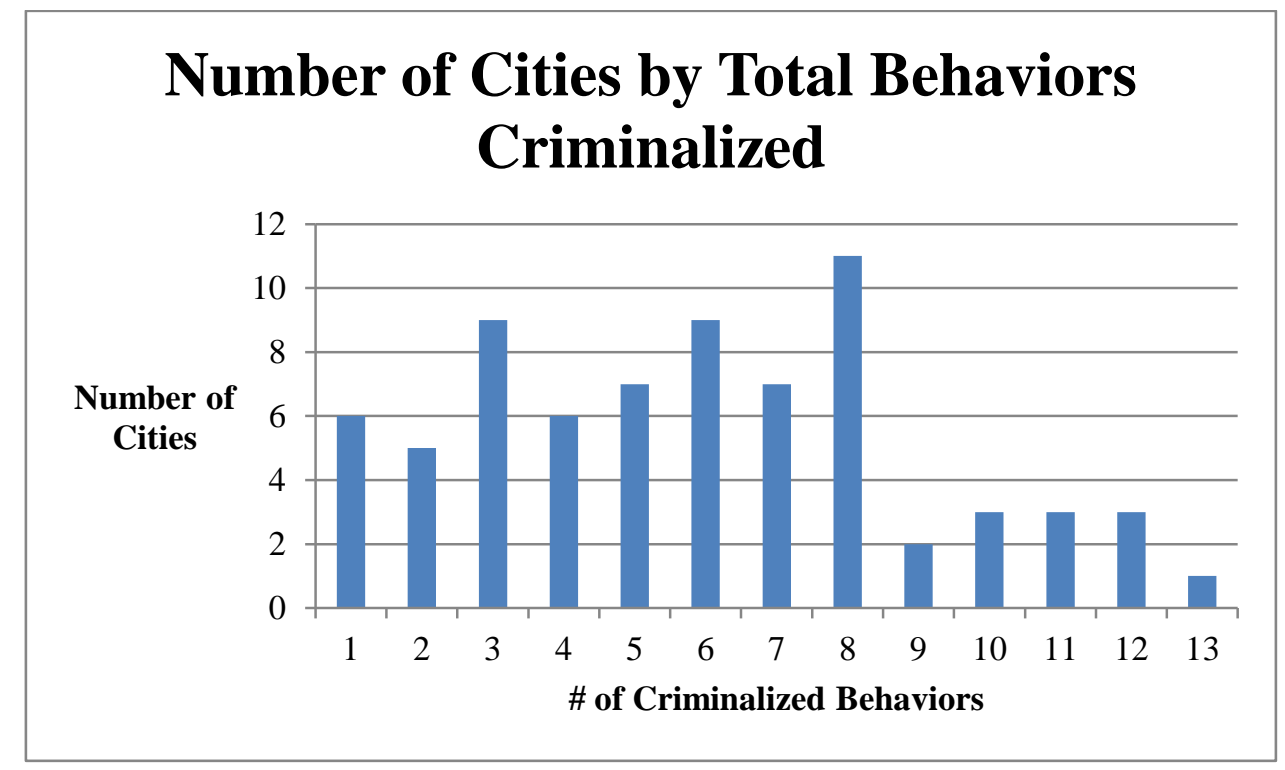

For a full summary of cities sorted by categories of behavior criminalized, please see the appendix. $^{18}$

The survey also revealed how many total ordinances a city has enacted that criminalize the conduct of necessary, life-sustaining activities. ${ }^{19}$ Generally, the number of enacted ordinances will mirror the number of criminalized behaviors; in other words, a single ordinance will criminalize a single behavior. However, a quirk exists wherever a city enacts either (1) a single ordinance that criminalizes multiple categories of conduct or (2) multiple ordinances that criminalize a single category of conduct. ${ }^{20}$ The former situation suggests a city is enacting fewer ordinances than other jurisdictions that are actually criminalizing categories of behavior at the

\footnotetext{
${ }^{17}$ The least offending municipalities criminalized only one behavior: Pullman, Tukwila, Ellensburg, Mill Creek, West Richland, and Ferndale. Of those six cities, 3 prohibited "camping in particular public places," while the other two prohibited "urination/defecation in public." Beyond those single-ordinance cities, five cities criminalized only two behaviors, and nine cities criminalized three behaviors.

${ }^{18}$ ORDINANCE DATA, supra note 15 , at Part XIV.

${ }^{19}$ ORDINANCE DATA, supra note 15 , at Part XV.

${ }^{20}$ Referred to in subsection D as compound ordinances and overlapping ordinances, respectively.
} 
same rate. The latter situation suggests a city is enacting more ordinances than other jurisdictions that are actually criminalizing categories of behavior at the same rate.

Unsurprisingly, the jurisdiction that criminalizes the broadest range of behaviorAuburn - also has enacted the highest number of criminalization ordinances (14). The next closest are Spokane and Pasco with (12), followed by a slew of municipalities at 11: Puyallup, University Place, Arlington, Bellingham, Everett, and Wenatchee.

\section{Legal and Policy Concerns: Overlapping and Compound Ordinances}

For purposes of clarity, legislative efficiency, and constitutional due process concerns, each ordinance should deal with a single type of behavior, and each restricted behavior should be addressed by just one ordinance. In synthesizing the survey results, researchers recognized that a majority of municipalities enacted ordinances that did not meet these parameters. Researchers termed these ordinances as either overlapping or compound, and then sought to quantify their presence among the surveyed jurisdictions.

\section{Overlapping Ordinances}

Overlapping occurs when a city criminalizes the same behavior under multiple ordinances. Besides the logistical concerns of reviewing duplicative prohibitions, overlapping ordinances create significant concern for homeless individuals and enforcement personnel. On a constitutional level, the discriminatory enforcement of these overlapping ordinances - such as using ordinances with higher penalties against one class of individuals versus others - gives rise to due process and equal protection concerns.

Under the example below, a homeless individual sitting on the sidewalk in Bellingham may be cited under either the Disorderly Conduct ordinance or the Pedestrian Interference ordinance for the exact same conduct. ${ }^{21}$

\section{Bellingham Municipal Code 10.24.010 Disorderly Conduct}

A person is guilty of disorderly conduct if he:

...

C. Intentionally obstructs pedestrian or vehicular traffic without lawful authority; or

\section{Bellingham Municipal Code 10.24.040 Pedestrian Interference}

A. A person is guilty of pedestrian interference if, in a public place, he or she intentionally:

1. Obstructs pedestrian traffic; or $\ldots$

Both the risk and the actual presence of constitutional violations could be pervasive throughout Washington. In a sample of seven cities, more than half (4 or 57\%) triggered potential legal and policy problems due to the presence of overlapping ordinances with differing

\footnotetext{
${ }^{21}$ These particular Bellingham ordinances highlight close parallels in language between duplicative ordinances. In this case, the constitutional concerns are lessened because both ordinances carry the same penalty. However, other case studies revealed stronger grounds for concern. See Spokane, infra Part III.B.3.
} 
penalties. $^{22}$ In fact, available enforcement data from one of these four cities further suggests that city may be enforcing the ordinances in a discriminatory way. ${ }^{23}$ Evidence of discriminatory enforcement in such a small sample size is alarming; this sampling reveals the minefield of potential danger to the rights of homeless people throughout the state of Washington and the very real likelihood of cities triggering those mines.

\section{Compound Ordinances}

Conversely, compound ordinances are single ordinances that criminalize multiple categories of behavior. These ordinances create a lack of transparency in the availability of public records. When a person is cited under a compound ordinance, researchers are unable to determine which conduct led to the citation. This "one fell swoop" process of drafting laws frustrates the ability for advocates to examine the true effects of criminalization, shrouding available data from analytical review. Again, pedestrian interference ordinances, such as the example below, are frequently written as compound ordinances.

Bellingham Municipal Code 10.24.040 Pedestrian Interference.
A. A person is guilty of pedestrian interference if, in a public
place, he or she intentionally:
1. Obstructs pedestrian traffic; or
2. Aggressively begs.
..

Transparency in the law is crucial for the thoughtful advancement of social policy. In preparing this brief, HRAP researchers scoured public municipal codes and submitted numerous requests for public records. The presence of compound ordinances frustrated these efforts by obscuring the picture painted by enactment and enforcement data. Without sufficient transparency, neither advocates nor policymakers can fully understand the true extent of, and purpose behind, criminalization efforts.

\section{Prevalence in Municipalities}

Having identified the problems associated with overlapping and compound ordinances, researchers created a formula to determine the prevalence of these types of ordinances throughout Washington. ${ }^{24}$ The formula provides that cities falling in the negative range have enacted more compound ordinances, while cities in the positive range have enacted more overlapping ordinances. ${ }^{25}$ The further away from zero a city is, the higher the number of

\footnotetext{
${ }^{22}$ These four cities include Pasco, Burien, Vancouver, and Spokane.

${ }^{23}$ This city is Spokane, described in greater detail in Part III.B.3.

${ }^{24}$ The formula researchers created required tallying up the total number of offending ordinances a city has enacted, and then subtracting the number of criminalized categories of behavior. A numerical representation of the formula: (\# of ordinances) - (\# of behaviors prohibited).

${ }^{25}$ This methodology may not be true in all instances. It is conceivable that a city has enacted both overlapping and compound ordinances that would cancel one another out in the formula. But the formula is a helpful way of
} 
overlapping or compound ordinances it has enacted. The results of this formula are detailed by the following graph:

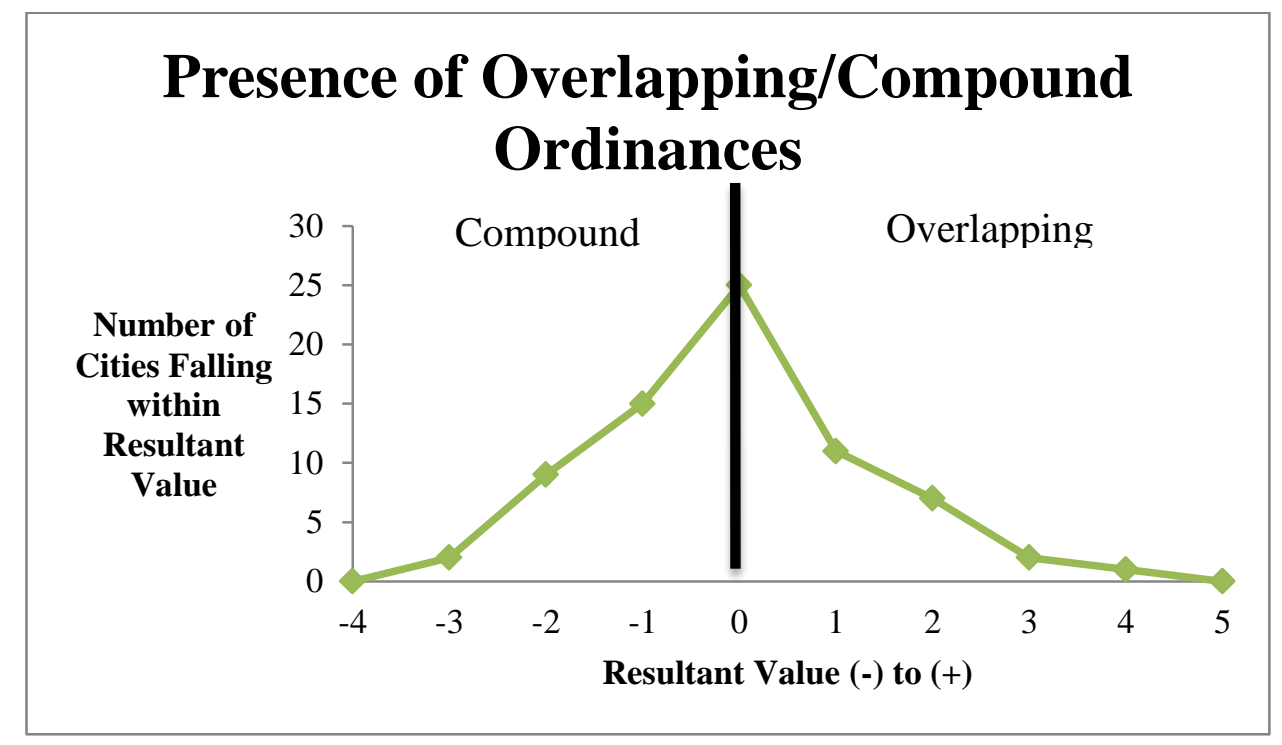

The results suggest widespread abuse of overlapping and compound ordinances. The graph indicates that only 25 municipalities mirrored their enacted ordinances to criminalized conduct at a 1:1 ratio, which means that at least 48 cities $(66 \%)$ have either compound or overlapping ordinances. Furthermore, 26 municipalities (36\%) used more overlapping ordinances, while 22 cities $(30 \%)$ used more compound ordinances. ${ }^{26}$ Accordingly, at least twothirds of surveyed Washington cities contain either transparency issues or constitutional violations, or both.

\section{WASHINGTON ENFORCEMENT DATA}

After charting the homelessness criminalization ordinances across Washington, researchers sought data regarding the enforcement of those ordinances. This section examines enforcement of homeless criminalization ordinances in the following six cities: Seattle, Bellingham, Spokane, Vancouver, Burien, Auburn, and Pasco. ${ }^{27}$

This section sheds light on how Washington cities are enforcing these ordinances through the police, the city attorney's office, and the judiciary. Police officers across the country face heightened scrutiny as a national debate unfolds regarding their dual roles as peacekeepers and public servants. Meanwhile, the city attorney's office and judiciary struggle with an overwhelming caseload involving defendants who are a far cry from being criminal predators.

discerning possible scenarios without being forced to manually go through the entire 73 city chart, thus saving these and future researchers valuable time. Furthermore, the cancellation effect would cause these results to be underinclusive, and is not a flaw that would skew these results to show an effect that in reality is not present.

${ }^{26}$ ORDINANCE DATA, supra note 15 , at Part XVI.

${ }^{27}$ After cataloguing the first 25 cities, researchers picked the top five with the broadest range of criminalized behaviors. Researchers then added Seattle as the most populous city, and then added Burien as a result of the recently passed "body odor" ordinance. For a more thorough discussion of the enforcement data methodology, see infra Appendix IV. 
Accordingly, the criminalization of homelessness impacts these groups in distinct ways, and each group is an important participant in the policy discussion.

A police officer's perspective of homeless criminalization affects his or her decision whether to issue a citation to a homeless individual in violation of an ordinance. In many cases, a homeless individual may not even know that the conduct - often necessary to their very survival - is considered unlawful and grounds for punishment. At that moment, police officers serve the dual functions of legal enforcer and community advocate. In other situations, police officers may find their hands tied when responding to complaints made by business owners or members of the public. ${ }^{28}$

Similarly, homeless criminalization has caused a shift in public perspective regarding the proper role of courts. A large percentage of homeless defendants suffer from mental health or substance abuse issues. ${ }^{29}$ These defendants inevitably violate a criminalization ordinance and, rather than receiving the treatment they need, are brought before the court. As a result, municipal courts are now "held accountable for the failures of the social service system." " Even prosecuting attorneys recognize that in some cities "the mental health system is nearly nonexistent and the criminal justice system is utilized as a default system."31

While all judges "seek to do good," 32 there are many different avenues to achieve that goal. Some judges tend to give deference to the prosecutor's recommendations, viewing jail as one piece of a rehabilitative program for mental health or substance abuse treatment. ${ }^{33}$ Other judges strongly believe that "the purpose of jail is to get predators off the street." 34 Experienced judges are more likely to intervene when they believe that defendants are not truly a danger to society. ${ }^{35}$ For example, in Seattle, cases of sleeping in doorways prosecuted as criminal trespass can be dismissed under the city's de minimis law. ${ }^{36}$ Despite the broad scope of judicial discretion, municipal courts are ill-equipped to fill the void left by underfunded social services programs. The courts are an inadequate means of addressing the problem of homelessness.

This section presents general findings and trends identified from the enforcement data, followed by specific data from each of the seven case study cities. Notably, researchers found

\footnotetext{
${ }^{28}$ See, e.g., interview by Bridget Barr and Joseph Ostrowski of Officer Daniel McCormack, Colorado Springs Police Department Homeless Outreach Team, SeATTLE University HomEless Rights AdvocACy ProjeCt (Feb. 20, 2015). Officer McCormack noted that "most of an officer's contacts with homeless individuals are based on calls from the public ...."

${ }^{29}$ See Kaya Lurie \& Breanne Schuster, Seattle University Homeless Rights Advocacy Project, DISCRIMINATION AT THE MARGINS: THE INTERSECTIONALITY OF HOMELESSNESS AND OTHER MARGINALIZED GROUPS (Sara Rankin ed., 2015).

${ }^{30}$ Interview with the Honorable Judith Hightower, Seattle Municipal Court, SEATTLE UNIVERSITY HOMELESS RigHTS ADVOCACY PROJECT (Mar. 10, 2015).

${ }^{31}$ Interview with Carla Lee, Deputy Chief of Staff, King County Prosecuting Attorney's Office, SEATTLE UNIVERSITY HOMELESS RIGHTS ADVOCACY PROJECT (Mar. 2, 2015).

${ }^{32}$ Interview with the Honorable Judith Hightower, Seattle Municipal Court, SEATTLE UNIVERSITY HOMELESS RighTS ADVOCACY PROJECT (Mar. 10, 2015).

${ }^{33}$ Id.

${ }^{34}$ Id.

${ }^{35} \mathrm{Id}$.

${ }^{36} I d$.
} 
that (1) income disparity predicts ordinance enforcement in nearly all of the case study cities; (2) Washington follows national trends for sit/lie ordinances but also exhibits a greater emphasis on public urination and "aggressive panhandling" ordinances; and (3) distinctions between civil and criminal ordinances allow cities to manipulate the different ways to incarcerate homeless defendants.

\section{A. General Findings and Trends}

\section{Predicting Enforcement: The Effects of Income Disparity}

Based on the case study cities, researchers determined that income disparity predicts aggressive enforcement of criminalization ordinances. ${ }^{37}$ Income disparity, as used in this section, refers to the percentage of a city's wealth concentrated in the wealthiest $5 \%$ compared to the poorest $20 \%{ }^{38}$ Visible poverty increases as a city's wealth becomes increasingly inaccessible to the poorest $20 \%$. This increased visibility might trigger efforts to "clean up the streets" by lawmakers and influential business owners. ${ }^{39}$

Of course, numerous political and societal factors also play a role in greater efforts to enforce criminalization ordinances. However, the graph below demonstrates that, with the exception of Burien, a rising income disparity gap (red) is generally matched by rising citation numbers (blue) when cities are compared to one another:

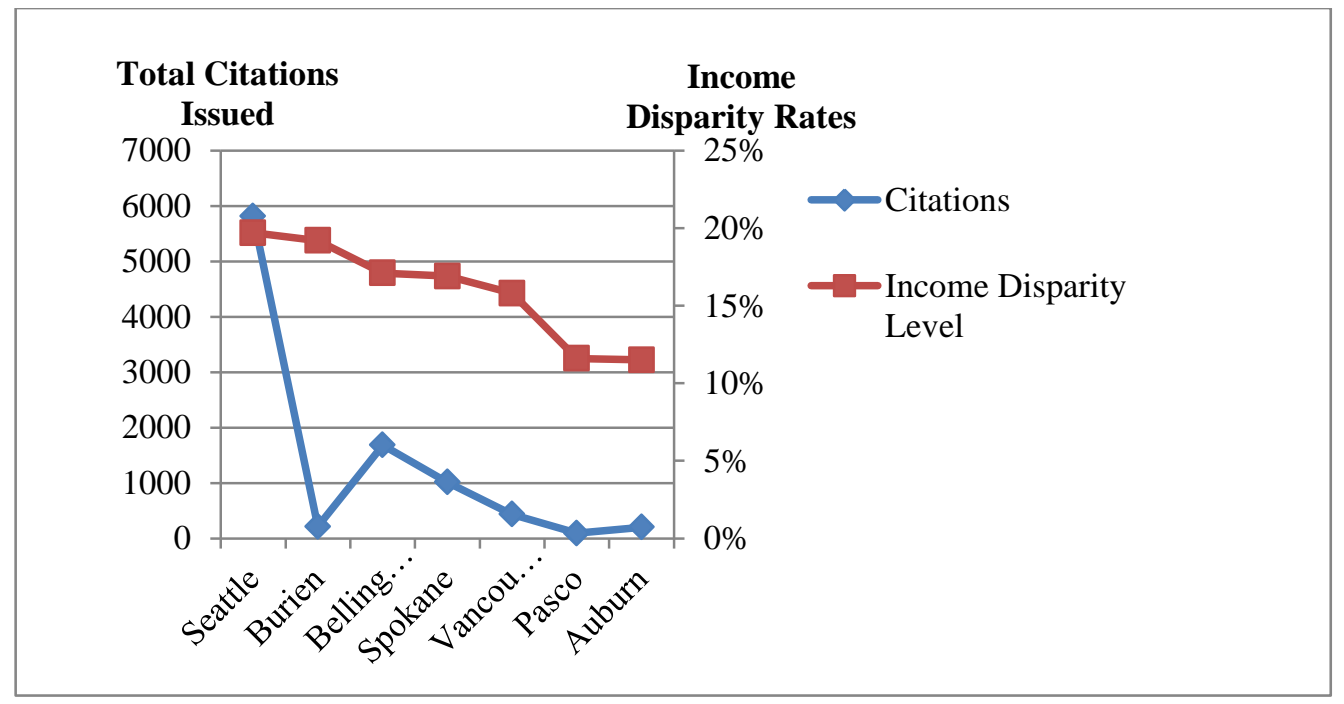

\footnotetext{
${ }^{37}$ HRAP researchers analyzed other factors such as total population, population density, rates of ordinance enactment. Of course, there are additional factors that may impact either enforcement, such as racial demographics and local economic trends. These factors may be the subject of future research.

${ }^{38}$ Levi Pulkkinen, Income Inequality: Which Washington City is Worst?, SEATTLE Post-InTELLIGENCER, (Nov. 7 , 2012), http://www.seattlepi.com/local/article/Income-inequality-Which-Washington-city-is-worst4004464.php\#photo-3682135.

${ }^{39}$ See Ortiz \& Dick, supra note 4. Mr. Ortiz and Mr. Dick discuss the "Broken Windows Theory" of visible poverty leading to fears of increased crime.
} 


\section{Comparing Local Enforcement to National Trends}

Researchers observed several key similarities between Washington State and national data. Police cited individuals for obstructing sidewalks or public places more than any other behavior; likewise, a national survey reported that $77 \%$ of homeless individuals were harassed and cited for sitting or lying down. ${ }^{40}$ In addition, cities with higher populations enforced their sit/lie ordinances more than cities with lower populations. ${ }^{41}$ Other frequently criminalized behaviors in Washington - such as public urination and aggressive panhandling - may not have been accounted for in national studies that focus on laws prohibiting sitting, standing, and lying down.

In Washington specifically, Seattle led the pack with a total of 5,814 citations issued during the five year period-more than $60 \%$ of all citations from all seven case study cities. At this rate, Seattle police issued an average of three citations per day over the five year period. Notably, $70 \%$ of Seattle citations were issued under an ordinance criminalizing sleeping in particular public places (detached campers or trailers specifically). ${ }^{42}$ On the other hand, Auburn issued relatively few citations (203), despite having a higher total number of ordinances than any other city (14). ${ }^{43}$

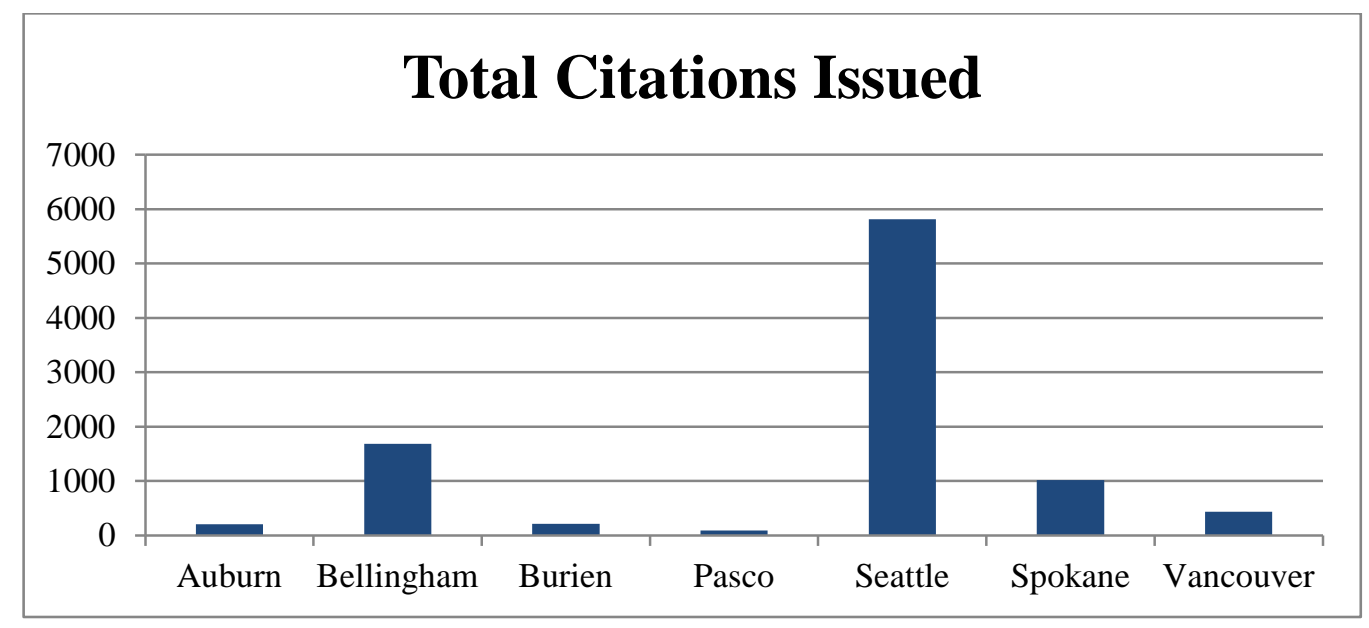

3. Civil vs. Criminal: To Jail or Not To Jail

One critical limitation of the data is the distinction between civil and criminal ordinance designations. Specifically, when an ordinance is listed as a civil infraction, the penalties may include fines but not incarceration. Thus, data relating to judicial disposition and incarceration was limited only to those ordinances listed as "criminal." For some cities, this could be a fraction of the ordinances.

\footnotetext{
${ }^{40}$ National Civil Rights Outreach Fact Sheet, W. Reg'l Advocacy Project (April 5, 2013), available at http://wraphome.org/images/stories/pdffolder/NationalCivilRightsFactSheetMarch2013.pdf.

${ }^{41}$ The first, second, and fourth most populous case study cities had the second, first, and third highest number of citations under these ordinances, respectively. ORDINANCE DATA, supra note 15, at Part XI.

${ }^{42}$ SMC 11.72.430.

${ }^{43}$ Practicum researchers looked only at municipal codes. Additional enforcement may occur under separate code sources such as administrative codes.
} 
In addition, designating an ordinance as a civil infraction also creates the potential for due process concerns. An individual cited under a civil ordinance does not have a right to counsel or to a jury trial. If the individual fails to pay the fine, a bench warrant might be issued for their arrest. Some cities, such as Seattle, have specific ordinances triggering misdemeanor penalties when an individual fails to respond to a civil infraction. ${ }^{44}$ Alternatively, some ordinances have written in a mechanism to convert to criminal penalties for repeat offenders. ${ }^{45}$ Not surprisingly, homeless defendants are unlikely to be able to pay these citations or to make a scheduled court appearance. Thus, an entire category of criminalization data currently lacks sufficient transparency for HRAP to incorporate into this report.

When an individual is ultimately picked up on a bench warrant, the court considers whether they failed to pay the fine without considering whether they committed the underlying infraction. In this case, homeless defendants lose their "day in court" yet may end up in jail all the same. For example, HRAP researchers discovered evidence of a city council using this distinction in an alarming way: removing criminal penalties simply to prevent homeless defendants from prevailing with sympathetic juries. ${ }^{46}$ Although in some ways this change seems to de-escalate the criminalization of homelessness, the manipulation of penalties is problematic for two key reasons: (1) as explained earlier, even civil infractions frequently escalate to criminal violations because homeless defendants often cannot pay their fines; and (2) the morphing of a criminal violation into a civil infraction, without explicit provisions to the contrary, strips homeless defendants of their rights to counsel and a jury trial. ${ }^{47}$

The attractiveness and utility of the civil/criminal distinction to cities is reinforced by an exceptional Burien ordinance granting unfettered discretion to move fluidly between each as the city sees fit. Under this law, the city can enforce any regulation as either civil or criminal, even if specific penalties are written into the criminalization ordinances themselves. ${ }^{48}$ This boundless discretion represents a grave threat of discriminatory abuse against anyone with whom the city takes issue, especially the homeless.

\footnotetext{
${ }^{44}$ SMC 12A.02.085. The City of Seattle informally provided information that suggests a decline in failure to respond cases. In 2008, almost 400 failure to respond cases were brought under this ordinance; in 2009, Seattle pursued over 450 failure to respond cases. But in 2013, the Seattle City Attorney's Office instituted a policy limiting the enforcement of this ordinance to those cases involving numerous civil infractions, and only after "reasonable attempts" had been made to engage the individual in services to resolve the problem. The City further provided information suggesting that the number of cases brought under the ordinance had dropped to just a handful in 2013 and 2014. Such policies, which suggest mindfulness of the disproportionate and unfair impact of failure to respond prosecutions on visibly poor people, are a positive development. Of course, a new administration could easily revoke this policy. A clearer and more permanent solution is to repeal laws that criminalize visible poverty and to enact laws that stop the cycle of criminalization.

${ }^{45}$ For example, Seattle's public urination ordinance (SMC 12A.10.100) provides that "Any person who violates this section and previously has either violated this section or has failed to appear as directed when served with a citation and notice to appear for a violation of this section is guilty of a misdemeanor."

${ }^{46}$ Interview by Bridget Barr and MJ Osman of David Harrison, Partner at Miller \& Harrison, LLC, SEATTLE UNIVERSITY HOMELESS RIGHTS ADVOCACY PROJECT. Because homeless defendants were prevailing with sympathetic juries on an anti-camping ordinance using the necessity defense, one city council restructured the ordinance to be civil rather than criminal.

${ }^{47}$ For a more thorough discussion of the "criminal versus civil" distinction, see Howard \& Tran, supra note 3.

${ }^{48}$ Burien Municipal Code 1.15.080. Of the ordinances listed for Burien, only two failed to have a penalty listed within the ordinance itself.
} 
A review of the ordinances from the case study cities below reveals that most cities lean toward criminal ordinances. With the exception of Seattle, which had only one criminal ordinance, all of the case study cities had as many or more criminal ordinances than civil. A visual representation of the civil and criminal ordinances for each city is as follows:

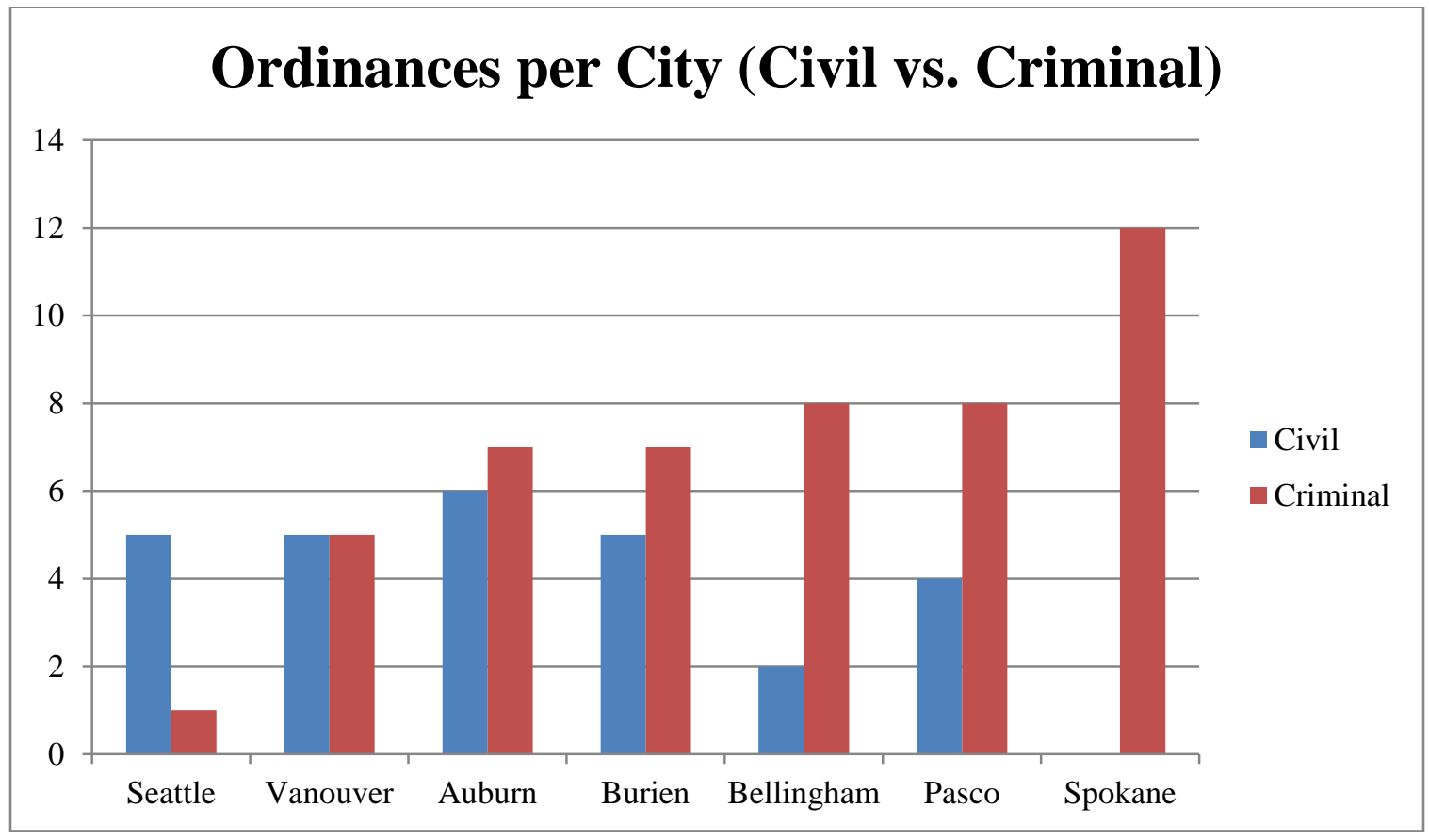

\section{B. Under the Microscope: A Case Study of Seven Cities}

The case studies below illustrate an important cross-section of available data. ${ }^{49}$ These cities present a variety of geographical locations, populations, and income disparity levels. However, they all (in some way or another) present distinct difficulties for homeless individuals whether through variety of ordinances, quantity of citations, or quality of the laws passed.

\section{Seattle $e^{50}$}

Population (in 2010):

608,660

Persons Below Poverty Level: $\quad 13.2 \%$

Total Housing Units:

308,516

Land Area in Square Miles:

83.94

Total Number of Business Firms: ${ }^{51} \quad 73,997$

Median Household Income:

$\$ 63,470$

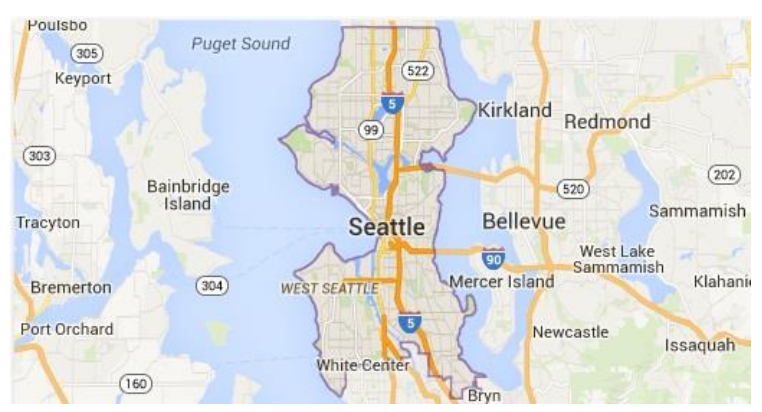

\footnotetext{
${ }^{49}$ Cities are presented below in the order of most-to-least citations issued.

${ }^{50}$ City-specific facts were obtained from the 2010 United States Census. U.S. Department of Commerce, State \& County QuickFacts, UNITED STATES CENSUS BUREAU, http:/quickfacts.census.gov/qfd/states/53000.html (last visited Mar. 11, 2015). Map data (2015 Google.

${ }^{51}$ The Census defines a firm as "a business organization or entity consisting of one domestic establishment (location) or more under common ownership or control."
} 
As the most populous city in the state, Seattle likely has the highest concentration of homeless citizens out of any Washington city. The recent One Night Count revealed at least 3,772 unsheltered individuals living in King County, a 20\% increase from 2014. ${ }^{52}$ Another estimate ranks Seattle fourth in the country for largest homeless population in metropolitan areas. ${ }^{53}$ On March 30, 2015, the city council unanimously passed several ordinances providing regulated homeless encampments and nearly $\$ 400,000$ in funding for additional shelter beds. ${ }^{54}$

\section{i. Citations}

Although Seattle has an average number of criminalization ordinances (6), it issues more citations than any other surveyed city: a total of 5,814 citations during the requested five year period (or an average of three citations per day). Of those, the most frequently cited behaviorby a large margin - was for sleeping/camping in public places $(4,117$ or $71 \%)$. ${ }^{55}$ After that, the other behaviors receiving citations were urinating or defecating in public $(1,004$ or $17 \%) ;{ }^{56}$ aggressive panhandling (349 or $6 \%) ;{ }^{57}$ sitting or lying in particular public places $(250$ or $4 \%) ;{ }^{58}$ and camping in particular public places $(94$ or $2 \%) .{ }^{59}$ No citations were reported during the five year period for storing personal property in public.

Citation issuance over time reveals a general downward trend with a couple notable exceptions. In 2010, for reasons as yet unclear to HRAP researchers, citation issuance spiked across the board in every category. ${ }^{60}$ Since 2010 , there has been a general decrease in citations over the years with the exception of Seattle's "Camper/Trailer Detached" ordinance, which dropped in numbers but has generally remained steady since 2011. ${ }^{61}$ Additionally, citations for Pedestrian Interference did not drop until 2012; yet, even through 2013, the total citations remained higher than the number issued in $2009 .{ }^{62}$

\footnotetext{
${ }^{52}$ Michael Konopasek, King Co. Homeless Population up by More Than 20 Percent, KING 5 NeWs (Feb. 4, 2015), http://www.king5.com/story/news/local/seattle/2015/01/23/king-county-homeless-count/22210763/.

53 John Ryan, After 10-Year Plan, Why Does Seattle Have More Homeless Than Ever?, KUOW.org (Mar. 3, 2015), http://kuow.org/post/after-10-year-plan-why-does-seattle-have-more-homeless-ever.

${ }^{54}$ City of Seattle, Full Council of 3/30/15, SeATtLeChannel.org (Mar. 30, 2015), http://www.seattlechannel.org/mayor-and-council/city-council/full-council?videoid=x53504.

55 This particular ordinance, SMC 11.72.430, is listed as "Trailer/Camper Detached" and prohibits a trailer or camper from being parked on any street.

${ }^{56}$ SMC 12A.10.100.

${ }^{57}$ SMC 12A.12.015.

${ }^{58} \mathrm{SMC} 15.48 .040$.

${ }^{59}$ The ordinance prohibiting aggressive panhandling also prohibits obstruction of sidewalks or public places (SMC 12A.12.015-entitled "Pedestrian Interference"). Accordingly, the 349 citations could be for any combination of those two behaviors.

${ }^{60}$ HRAP hopes to perform additional research on this point in the future.

${ }^{61}$ This ordinance is included because of historical efforts throughout the country to prevent homeless people from sleeping or camping in their vehicles. See, e.g., Ian Lovett, When Home Has No Place to Park, THE NEW YORK TIMES (Oct. 3, 2010), available at http://www.nytimes.com/2010/10/04/us/04rv.html?_r=1. Other examples of creative criminalization include "scofflaw" ordinances that accelerate vehicle impoundment for unpaid parking tickets (SMC 11.35.010) and Driving While License Suspended ordinances creating a cycle of infractions for being unlicensed (SMC 11.56.320).

${ }^{62}$ For a complete chart of ordinances over time, see ORDINANCE DATA, supra note 15, at Part V.
} 
Seattle had only one instance of overlapping ordinances relating to camping in public. However, the circumstances under each ordinance appeared to be sufficiently distinct. One ordinance deals with camping in parks specifically, while the other ordinance deals with parking campers and trailers on the street. ${ }^{63}$

\section{ii. Case Dispositions}

Researchers were particularly interested in the disposition data for citations because of a peculiar discrepancy: although citation disposition data was robust, information relating to consequent fines and penalties was minimal. While a majority of citations were paid in full $(2,919)$, nearly a third of all citations were listed as defaulted $(1,881)$. The consequence of defaulting on a civil infraction is the imposition of an additional fine and referral to an outside collection agency. ${ }^{64}$ However, because the collection agency is a private business contracted with the court, HRAP researchers did not have access to data on those fines.

\section{Seattle Citation Disposition}

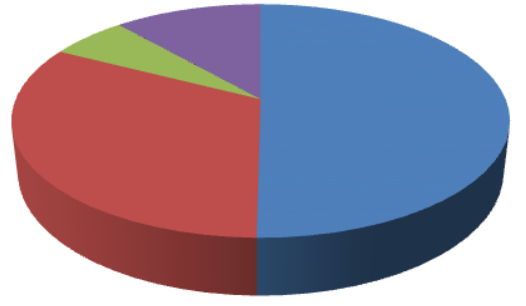

- Paid in Full

Defaulted

Dismissed

Other

With regard to Seattle's criminal Pedestrian Interference ${ }^{66}$ ordinance, the court reported that additional fines for failing to appear are issued under a particular ordinance, yet no fines had been issued under that law since 2002. ${ }^{67}$ The conclusion must be either that the court has consistently declined to enforce monetary penalties for failing to appear, or that data relating to such penalties are simply unavailable through the court's case tracking system.

\section{iii. Sentencing}

Under the Pedestrian Interference ordinance, 134 bench warrants were issued and 123 individuals were sentenced to time in custody during the five year period. The complete breakdown is as follows:

\footnotetext{
${ }^{63}$ SMC 18.12.250 and 11.72.430, respectively.

${ }^{64}$ The court the court contracts with AllianceOne, a private collections agency. AllianceOne attempts to collect on the debt for 10 years, after which time the debt is "written off by the [c]ourt." A complete copy of the Court's contract with AllianceOne may be found here: http://web6.seattle.gov/FAS/SummitPan/R296/R296.Result.aspx?PoStatus=2\&SearchType=2\&SearchTerm=allianc e.

${ }^{65}$ Other categories described by the court include: deferred, pending, closed, cancelled, dispositional continuance, failure to appear, no complaint filed, obligations satisfied, pre-trial diversion, suspended sentence.

${ }^{66}$ Pedestrian Interference, SMC 12A.12.015.

${ }^{67}$ SMC 12A.28.070.
} 


\begin{tabular}{|l|l|l|l|l|l|l|l|}
\hline Category & 1-2 days & $\mathbf{3 - 7}$ days & $\begin{array}{l}\mathbf{8 - 1 4} \\
\text { days }\end{array}$ & $\begin{array}{l}\text { 15-30 } \\
\text { days }\end{array}$ & $\begin{array}{l}\text { 31-60 } \\
\text { days }\end{array}$ & $\begin{array}{l}\text { 61-90 } \\
\text { days }\end{array}$ & $\begin{array}{l}\text { 91-365 } \\
\text { days }\end{array}$ \\
\hline $\begin{array}{l}\text { Aggressive } \\
\text { Panhandling }\end{array}$ & $9(7 \%)$ & $6(5 \%)$ & $9(7 \%)$ & $12(10 \%)$ & $4(3 \%)$ & $45(37 \%)$ & $38(31 \%)$ \\
\hline
\end{tabular}

Seattle data suggests sentencing for aggressive panhandling is fairly erratic. Defendants charged with aggressive panhandling risk up to a year in jail. Many factors go into a court's sentencing decision: the circumstances surrounding the infraction, the egregious nature of the offense, the existence of prior warrants, and the defendant's criminal history. For example, Seattle data shows that high jail times were commonly (but not always) imposed when additional violations had been included. ${ }^{6}$ On the other hand, a number of aberrations stood out. One defendant spent 365 days in jail for obstructing a public officer and pedestrian interference, while another defendant spent 364 days in jail under only the pedestrian interference ordinance. ${ }^{69}$ Future research and investigation could help to clarify potential issues with the factual scenarios found to constitute aggressive panhandling and whether these factual scenarios seem to warrant the imposition of maximum sentences.

“Aggressive panhandling” ordinances, such as Seattle's Pedestrian Interference ordinance, represents a drafting effort to target homeless people specifically. Panhandling by itself is an act protected by the First Amendment. ${ }^{70}$ In Seattle, panhandling becomes "aggressive" when the facts suggest an "intent to intimidate" such that a reasonable person would feel "fearful or compelled."71 This language is in nearly every aggressive panhandling ordinance throughout Washington State-yet cities often have laws already on the books that cover the same type of conduct, laws that are facially neutral and do not target a specific subsect of people. A side-by-side comparison of Seattle's Pedestrian Interference and Harassment ordinances demonstrates this point:

SMC 12A.12.015 - Pedestrian Interference.

A. The following definitions apply in this section:

1. "Aggressively beg" means to beg with the intent to intimidate another person into giving money or goods.

2. "Intimidate" means to engage in conduct which would make a reasonable person fearful or feel compelled.

....
SMC 12A.06.040 - Harassment.

A. A person is guilty of harassment if:

1. With the intent to annoy or alarm another person he/she repeatedly uses fighting words or obscene language, thereby creating a substantial risk of assault; or

2. Without lawful authority, the person knowingly threatens:

....

d. Maliciously to do any other act which is intended to substantially harm the person

\footnotetext{
${ }^{68}$ Search performed by going to www.seattle.gov/courts/ and selecting "Online Services" followed by "Look Up Case." As an example, case number 546485 received a sentence of 365 days but included charges for assault, harassment, and criminal trespass.

${ }^{69}$ Case numbers 551231 and 571215 respectively.

${ }^{70}$ U.S. v. Kokinda, 497 U.S. 720,725 (1990).

${ }^{71}$ SMC 12A.12.015.
} 
threatened or another with respect to his or her physical or mental health or safety; and

e. The person by words or conduct places the person threatened in reasonable fear that the threat will be carried out.

The comparison reveals that "aggressive panhandling" is nothing more than harassment in the context of a poor person asking for money. Aggressive panhandling ordinances impose a higher standard of conduct on homeless individuals, simply by virtue of asking for donations. Future research should be performed regarding: (1) how the burdens of proof compare; and (2) how the differing standards applied to the same conduct are reflected in the sentencing outcomes.

With regard to sentencing outcomes for Pedestrian Interference, the Seattle data reveals a startling trend toward imposing greater sentences. In 2009, the duration of jail time sentenced under this ordinance was relatively spread out. The same number of individuals received sentences of between 1-2 days in jail as did individuals sentenced to 31-90 days in jail, and those sentenced to greater than 30 days in jail accounted for $42 \%$ of all defendants. But by 2013, no defendant sentenced under this ordinance received less than 15 days in jail and $87 \%$ of all defendants were sentenced to more than 30 days in jail.

The below table illustrates this trend of increasing sentences given for pedestrian interference:

\begin{tabular}{|l|l|l|l|l|l|}
\hline CUSTODY TIME & $\mathbf{2 0 0 9}$ & $\mathbf{2 0 1 0}$ & $\mathbf{2 0 1 1}$ & $\mathbf{2 0 1 2}$ & $\mathbf{2 0 1 3}$ \\
\hline $\mathbf{1 - 2}$ days in custody & 6 & 1 & 1 & 1 & 0 \\
\hline 3-7 days in custody & 3 & 0 & 0 & 3 & 0 \\
\hline $\mathbf{8 - 1 4}$ days in custody & 2 & 4 & 3 & 0 & 0 \\
\hline $\mathbf{1 5 - 3 0}$ days in custody & 4 & 2 & 0 & 2 & 4 \\
\hline 31-90 days in custody & 6 & 10 & 9 & 8 & 15 \\
\hline 91+ days in custody & 5 & 9 & 5 & 3 & 12 \\
\hline
\end{tabular}

Seattle's homeless population continues to grow, and the city's response influences policymakers, enforcement personnel, city attorneys, and courts throughout the state. For better or for worse, Seattle is at the forefront of homeless policymaking in Washington. The data paints the picture of a house divided: on the one hand trying to de-escalate penalties by designating ordinances as civil infractions, yet on the other hand imposing increasingly severe jail sentences for violations of its remaining criminal ordinance. 


\section{Bellingham}

Population (in 2010):

80,885

Persons Below Poverty Level:

$22.6 \%$

Total Housing Units:

36,760

Land Area in Square Miles:

27.08

Total Number of Business Firms:

8,607

Median Household Income:

$\$ 40,844$

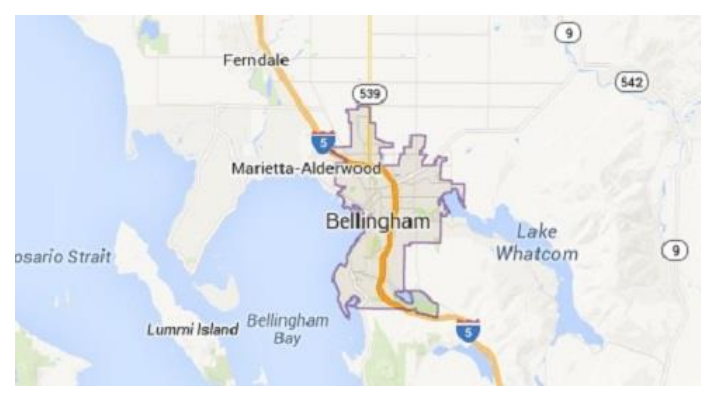

Just 21 miles south of the Canadian border, Bellingham describes itself as "the last major city before the Washington coastline meets the Canadian border."72 It is also the twelfth most populous city in the state. ${ }^{73}$ Out of all six of the case study cities, Bellingham has the secondhighest percentage of citizens who fall below the poverty level (after Pasco). ${ }^{74}$ Unfortunately, the data received from the city was comparatively minimal.

\section{i. Citations}

Bellingham reported a total of 1,682 citations issued during the requested five year period. The majority of citations were issued for obstruction of sidewalks/public places $(1,156$ or $69 \%) .{ }^{75}$ Bellingham also reported 400 citations for public urination or defecation $(25 \%)$ and 109 citations for sitting or lying in particular public places $(6 \%) .{ }^{76}$ Bellingham reported that no citations had been issued for the remaining eight ordinances identified by HRAP researchers.

Additionally, Bellingham has three overlapping ordinances covering the same type of conduct: obstruction of sidewalks or public places. However, the data did not reveal discriminatory fines or sentencing. All three ordinances are designated as misdemeanors punishable by a fine of up to $\$ 1,000$ and/or a jail sentence of up to 90 days.

\section{ii. Case Dispositions and Sentencing}

Unfortunately, Bellingham did not provide data regarding case dispositions and sentencing for the citations above. A review of the ordinance language revealed monetary penalties ranging from $\$ 75$ up to $\$ 250$. $^{77}$ Additional fees for failing to appear included a $\$ 100$ bench warrant fee and a $\$ 55$ booking fee if the defendant was booked into jail after the issuance

\footnotetext{
${ }^{72}$ About Bellingham, CITY OF BELLINGHAM, http://www.cob.org/visiting/about.aspx (last visited Dec. 4, 2014).

${ }^{73}$ U.S. Department of Commerce, supra note 50.

${ }^{74}$ Individuals below poverty level is based on the 2010 Census data.

75 This number derives from two overlapping ordinances: 1,127 citations under BMC 10.24.010 and 29 citations under BMC 10.24.040.

${ }^{76}$ BMC 10.24.020 and 10.24.070, respectively.

${ }^{77}$ Camping in particular public places $(\$ 75)$; sitting/lying in particular public places $(\$ 100)$; obstruction of sidewalks/public places (\$250); nuisances "offending public decency" (\$250); urination/defecation in public (\$200); and rummaging/scavenging (\$200).
} 
of a warrant. The data from Bellingham did not reveal how often these additional fines were assessed. $^{78}$

\section{Spokane}

Population (in 2010):

Persons Below Poverty Level:

Total Housing Units:

Land Area in Square Miles:

Total Number of Business Firms:

Median Household Income:
208,916

$18.7 \%$

94,291

59.25

18,017

$\$ 42,274$

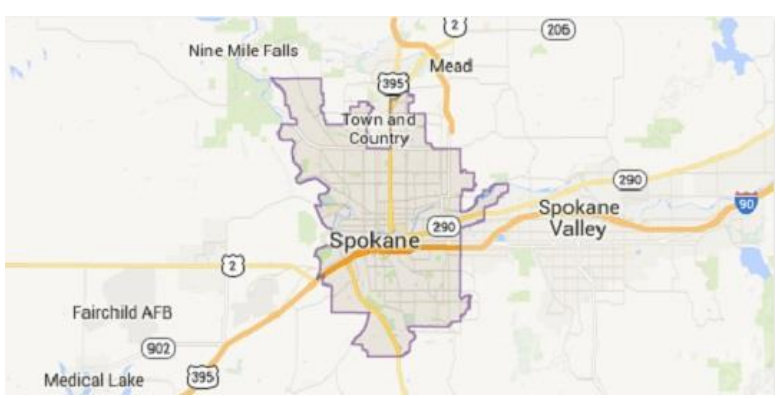

Located in Eastern Washington, Spokane is one of the last stops before passing over into neighboring Idaho. Nicknamed the "Lilac City," Spokane was originally one of the most productive mining districts in North America before diversifying to include other industries, such as telecommunications and financial services. ${ }^{79}$ Spokane is also the second most populous case study city and ties with Pasco as having the second highest number of homeless criminalization ordinances.

\section{i. $\underline{\text { Citations }}$}

Spokane was a particularly challenging case study because of its abundance of compound ordinances - that is, single laws prohibiting multiple types of conduct. Accordingly, Spokane's citation data is presented by ordinance with a notation as to which behaviors each ordinance criminalizes.

Over the requested five year period, Spokane reported a total of 1,015 citations and 759 warrants issued under those citations. Spokane's enforcement followed the state trend, with citations focused on sit/lie and aggressive panhandling ordinances. The specific breakdown is as follows:

\begin{tabular}{|l|l|c|c|}
\hline \multicolumn{1}{|c|}{ Ordinance } & \multicolumn{1}{|c|}{ Criminalized Behaviors } & $\begin{array}{c}\text { Total } \\
\text { Citations }\end{array}$ & $\begin{array}{c}\text { Total } \\
\text { Warrants }\end{array}$ \\
\hline 10.06 .015 & Urinating or defecating in public. & $72(7 \%)$ & $71(9 \%)$ \\
\hline 10.08 .030 & $\begin{array}{l}\text { Body odor; } \\
\text { Obstruction of sidewalks/public places. }\end{array}$ & $29(3 \%)$ & $17(2 \%)$ \\
\hline $10.08 \mathrm{~B} .040$ & Camping in particular public places; & $100(10 \%)$ & $169(22 \%)$ \\
\hline 10.10 .025 & $\begin{array}{l}\text { Sitting/lying in particular public places; } \\
\text { Obstruction of sidewalks/public places; }\end{array}$ & $462(46 \%)$ & $426(56 \%)$ \\
\hline
\end{tabular}

\footnotetext{
${ }^{78}$ Bellingham declined to provide any data with regard how many of the cited individuals were homeless, noting that such information would require "significant research or explanation." Instead, the city referred researchers to the Whatcom County Jail. Practicum researchers require a list of case numbers in order to request information from the jail; however, due to the municipal court's technological limitations, this list of case numbers could not be provided.

${ }_{79}$ Spokane, WA Metropolitan Statistical Area, FORBES, http://www.forbes.com/places/wa/spokane/ (last visited Mar. $31,2015)$.
} 


\begin{tabular}{|l|l|c|c|}
\hline & Aggressive panhandling. & & \\
\hline 10.10 .026 & $\begin{array}{l}\text { Sleeping in particular public places; } \\
\text { Sitting/lying in particular public places. }\end{array}$ & $21(2 \%)$ & $26(3 \%)$ \\
\hline 10.10 .040 & $\begin{array}{l}\text { Camping in particular public places; } \\
\text { Begging in particular public places. }\end{array}$ & $291(29 \%)$ & $1(0 \%)$ \\
\hline 10.10 .100 & Urinating or defecating in public. & $19(3 \%)$ & $49(6 \%)$ \\
\hline 10.19 .020 & Begging in public city-wide. & $0(0 \%)$ \\
\hline
\end{tabular}

Peculiarly, Spokane courts issued a higher number of warrants under specific categories than there were total citations. The reason for the discrepancy is currently unclear. ${ }^{80}$

With few exceptions, Spokane's data shows the city's increasing tendency to issue citations, almost across the board. In particular, citations for Pedestrian Interference in the last reported year (2013) were more than double any year prior. As the below chart depicts, citation issuances steadily increased for all but the Nuisance ordinance:

\begin{tabular}{|l|c|c|c|c|c|}
\hline \multicolumn{1}{|c|}{ CITATIONS } & $\mathbf{2 0 0 9}$ & $\mathbf{2 0 1 0}$ & $\mathbf{2 0 1 1}$ & $\mathbf{2 0 1 2}$ & $\mathbf{2 0 1 3}$ \\
\hline $\mathbf{1 0 . 0 6 . 0 1 5}$ - Urinating in Public & 0 & 0 & 1 & 29 & 42 \\
\hline $\mathbf{1 0 . 0 8 . 0 3 0}$ - Nuisance & 14 & 13 & 2 & 0 & 0 \\
\hline $\begin{array}{l}\text { 10.08B.040 - Occupy/Build } \\
\text { Transient Shelter }\end{array}$ & 1 & 4 & 8 & 23 & 64 \\
\hline $\begin{array}{l}\text { 10.10.025 - Pedestrian } \\
\text { Interference }\end{array}$ & 89 & 83 & 41 & 56 & 193 \\
\hline $\begin{array}{l}\text { 10.10.026 - Sit/Lie on Sidewalk } \\
\text { in Retail Zone }\end{array}$ & 3 & 1 & 5 & 2 & 10 \\
\hline $\begin{array}{l}\text { 10.10.040 - Public Park Rules } \\
\text { 10.10.100 - Unlawful Transit } \\
\text { Conduct }\end{array}$ & 7 & 42 & 75 & 25 & 61 \\
\hline \begin{tabular}{l} 
10.19.020 - Vagrancy \\
\hline
\end{tabular} & 0 & 0 & 0 & 0 & 12 \\
\hline
\end{tabular}

\section{ii. Case Dispositions and Sentencing}

Like Seattle, Spokane provided robust data regarding the disposition of each citation within the five year period. Unlike Seattle, however, citations under each ordinance were adjudicated and dismissed at a roughly equal rate. ${ }^{81}$ The following chart depicts the breakdown of citation dispositions:

\footnotetext{
${ }^{80}$ This issue warrants future study.

${ }^{81}$ For a breakdown of citation dispositions by ordinance, see ORDINANCE DATA, supra note 15, at Part VIII.
} 


\section{Spokane Citation Disposition}

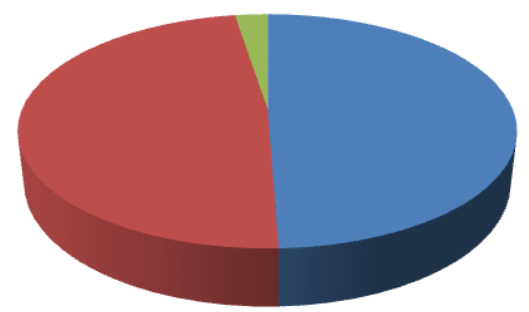

$\square$ Guilty

$\square$ Dismissed

Amended

Perhaps most striking were Spokane's statistics relating to the duration of time defendants spent in custody. On average, Spokane defendants spent anywhere between 3-30 days in custody for all but two of the ordinances. ${ }^{82}$ One ordinance prohibiting a broad range of conduct — sitting/lying in public places, obstructing sidewalks, and aggressive panhandling — led to both the highest number individuals in custody as well as the highest duration of time spent in custody. ${ }^{83}$ A visual representation of custody times is as follows:

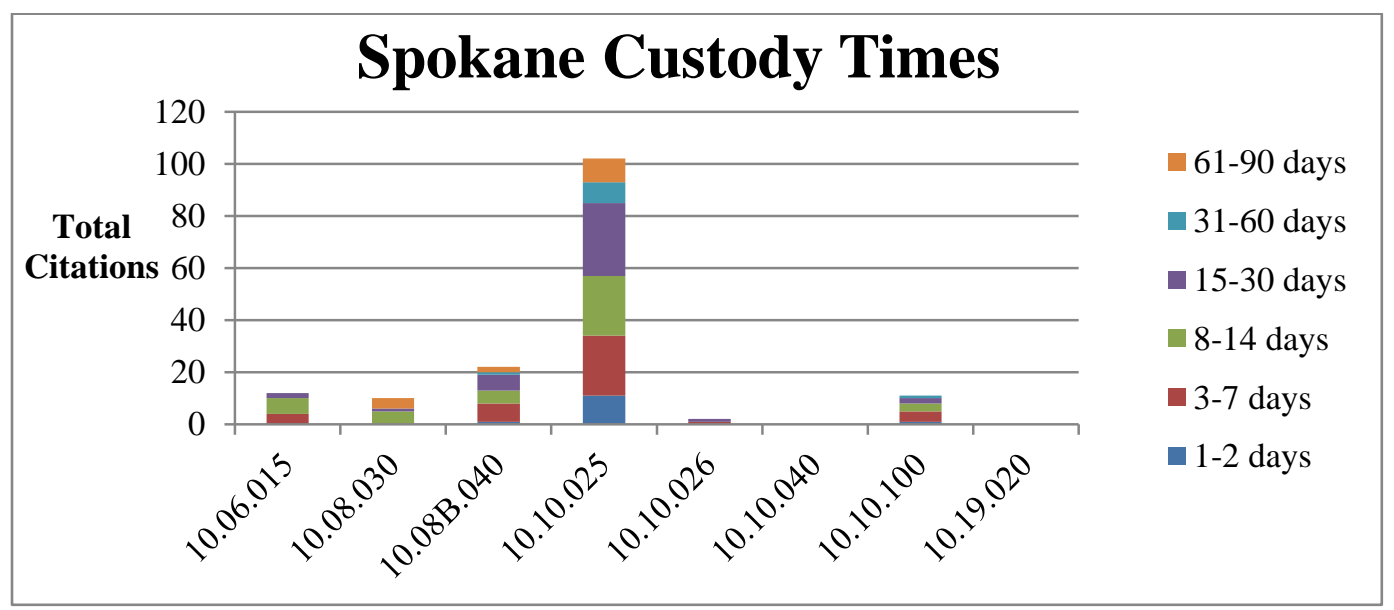

\section{iii. Overlapping Ordinance Concerns}

Spokane's data suggests a potential constitutional issue stemming from enforcement of overlapping ordinances. In general, Spokane's ordinances are punishable as misdemeanors resulting in fines up to $\$ 5,000$ and jail time of no more than one year. ${ }^{84}$ However, for camping in public places, Spokane has multiple ordinances punishing the same behavior yet providing for different penalties. ${ }^{85}$ Based on the enforcement data, Spokane police issue citations under the

\footnotetext{
${ }^{82}$ No defendants spent time in custody for SMC 10.10.040 (begging in particular public places) and SMC 10.19.020 (begging in public city-wide). For complete table of custody times per ordinance, see ORDINANCE DATA, supra note 15, at Part VIII.

${ }^{83}$ SMC 10.10.025. As with all custody time data, one inherent limitation is that the sentence imposed may be related to an additional charge brought at the same time as the homeless ordinance violation.

${ }^{84}$ See ORDINANCE DATA, supra note 15 , at Part X for complete table of punishment ranges.

${ }^{85}$ Spokane's ordinances criminalizing camping in public places include SMC 10.08B.040 and SMC 10.10.040.
} 
criminal ordinance in roughly $25 \%$ of cases compared to the alternate ordinance carrying only a civil penalty.

\section{Ordinances Prohibiting Camping in Particular Public Places}

\begin{tabular}{|l|l|c|c|c|c|}
\hline Citation & $\begin{array}{l}\text { Sentence } \\
\text { Range }\end{array}$ & $\begin{array}{l}\text { Citations } \\
\text { Issued }\end{array}$ & $\begin{array}{l}\text { Guilty / } \\
\text { Committed }\end{array}$ & Dismissed & $\begin{array}{l}\text { Amended / } \\
\text { Other }\end{array}$ \\
\hline 10.08 B.040 & $\begin{array}{l}\text { Up to } \$ 1,000 \\
\text { and jail up to } \\
90 \text { days }\end{array}$ & 94 & $20(21 \%)$ & $63(67 \%)$ & $11(12 \%)$ \\
\hline 10.10 .040 & Up to $\$ 250$ & 291 & $265(91 \%)$ & $20(7 \%)$ & $6(2 \%)$ \\
\hline
\end{tabular}

Not only are the camping ordinances overlapping, but the more criminal ordinance is also compound. $^{86}$ That ordinance targets camping in parks specifically but also camping on any street or publicly owned parking lot. Unfortunately, the data is unclear regarding which behavior the total citations account for. The criminal ordinance remains susceptible to discriminatory enforcement; even a single citation under the criminal ordinance for camping in the park would run afoul of constitutional equal protections and established legal principles.

Spokane's story is one of aggressive criminalization. Spokane's municipal code contains numerous instances of overlapping and compound ordinances. Furthermore, citation numbers rose dramatically over the past five years, despite courts dismissing nearly half of all citations. Coinciding with this sharp increase in criminalization, Spokane's code generates equal protection concerns as a result of its public camping and pedestrian interference ordinances. Perhaps more than any other case study city, Spokane's policy on homelessness encapsulates all of the problems inherent to criminalization.

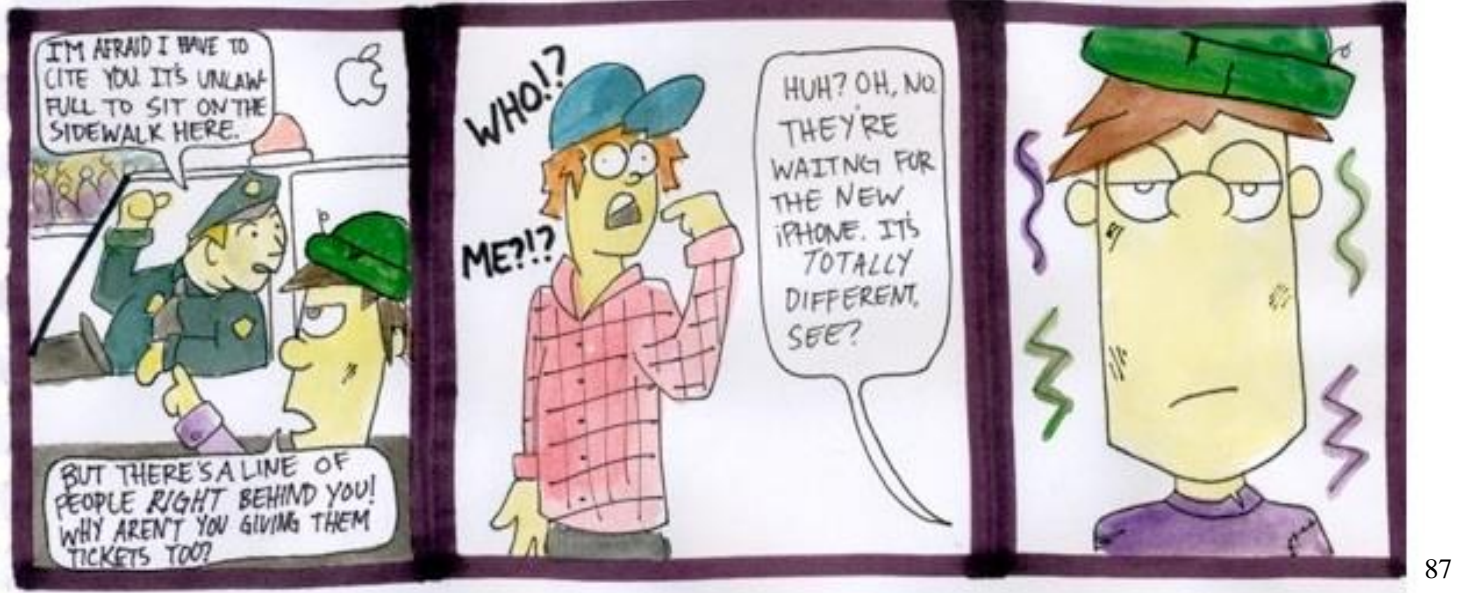

\footnotetext{
${ }^{86}$ SMC 10.08B.040.

${ }^{87}$ All comics prepared by Chris Lee, a local Seattle artist. Although adding some brevity to a serious issue, all comics are based on real news stories involving criminalization ordinances. For this comic, see Spokane Police Clarify Sit and Lie Ordinance, 590 KQNT, http://www.590kqnt.com/articles/northwest-news-119088/spokanepolice-clarify-sit-and-lie-12810881/ (last visited Mar. 11, 2015).
} 


\section{Vancouver}

Population (in 2010):

161,791

Persons Below Poverty Level: $\quad 16.0 \%$

Total Housing Units: $\quad 70,005$

Land Area in Square Miles: $\quad 46.46$

Total Number of Business Firms: $\quad$ 13,642

Median Household Income: $\quad \$ 49,271$

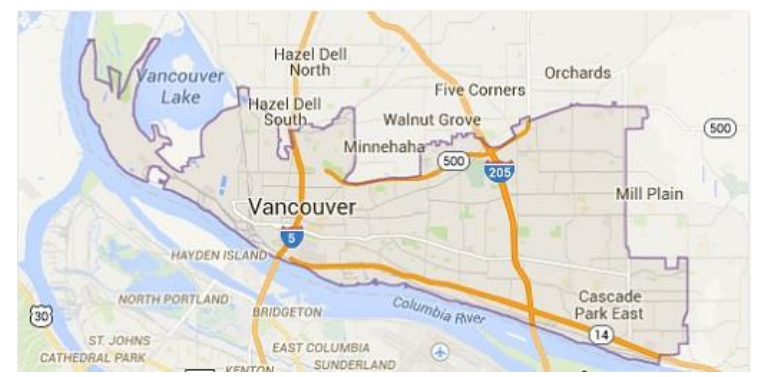

Located across the Columbia River from Portland, Oregon, Vancouver is the fourth most populous city in Washington. Vancouver's largest employers are PeaceHealth Southwest Medical Center, followed by Evergreen Public Schools and Vancouver Public Schools. ${ }^{88}$ Over the past decade, Vancouver has focused on revitalizing its downtown and waterfront regions, hoping to attract visitors and small businesses alike. ${ }^{89}$

\section{i. Citations}

In the requested five year period, Vancouver reported a total of 434 citations. Vancouver police issued the most citations under a compound ordinance that criminalizes both camping in public city-wide and living or sleeping in vehicles $(281$ or $64 \%){ }^{90}$ The next most commonly issued citations were for obstruction of sidewalks/public places (33 or $7 \%),{ }^{91}$ urinating or defecating in public (91 or $20 \%),{ }^{92}$ aggressive panhandling (29 or 6\%), ${ }^{93}$ scavenging (18 or $2 \%),{ }^{94}$ storing personal belongings in public ( 9 or $\left.1 \%\right),{ }^{95}$ and a provision allowing trespass warnings to be given ( 1 or less than $1 \%) .{ }^{96}$

\section{ii. Case Dispositions and Sentencing}

According to the City, the vast majority of the citations above reached a plea agreement (345), while only a fraction were contested in court (48). ${ }^{97}$ The details of such plea agreements, along with the City's motivations to favor them, are unclear. Regrettably, Vancouver did not provide any additional information regarding the citations or sentencing.

\footnotetext{
${ }^{88}$ Financial \& Management Services, Comprehensive Annual Financial Report at 186, CITY OF VANCOUVER, http://www.cityofvancouver.us/sites/default/files/fileattachments/financial_and_management_services/page/1060/cit yofvancouver2012cafr.pdf (last visited Mar. 31, 2015).

${ }^{89}$ Community \& Economic Development, Destination Downtown, CITY OF VANCOUVER, http://www.cityofvancouver.us/ced/page/destination-downtown (last visited Mar. 31, 2015).

${ }^{90} \mathrm{~V} 8.22 .040$.

9129 of these citations derive from a compound ordinance, V7.04.020, which prohibits two types of behavior: obstruction of sidewalks/public places and aggressive panhandling.

${ }^{92}$ V7.10.020.

${ }^{93}$ V7.04.020.

${ }^{94} \mathrm{~V} 6.12 .216$.

${ }^{95} \mathrm{~V} 8.22 .050$.

${ }^{96}$ V15.04.170.

${ }^{97}$ Defined as receiving a guilty verdict or a dismissal. For a complete breakdown of disposition numbers, see ORDINANCE DATA, supra note 15, at Part VII.
} 


\section{iii. Overlapping Ordinance Concerns}

Vancouver has three overlapping ordinances prohibiting obstruction of sidewalks or public places. The three ordinances are labeled as nuisances, pedestrian interference, and obstruction on a bus or in a bus station. ${ }^{98}$ The nuisance ordinance is listed as a civil infraction, yet the pedestrian interference and bus obstruction ordinances are listed as misdemeanors. Vancouver reported no citations under either the nuisance or the bus obstruction ordinance, and only 29 citations under the pedestrian interference ordinance. However, the possibility remains for discriminatory enforcement under the language of these laws.

\section{Burien}

Population (in 2010):

33,313

Persons Below Poverty Level:

Total Housing Units:

$17.8 \%$

14,322

Land Area in Square Miles:

7.42

Total Number of Business Firms:

2,998

Median Household Income:

$\$ 50,595$

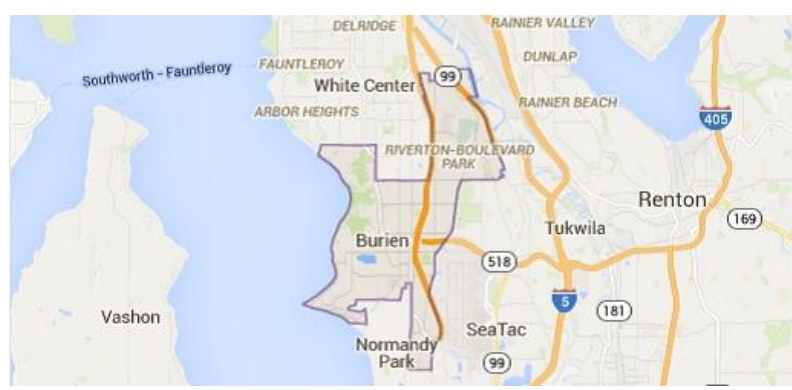

Burien has received national attention for recently adopting Chapter 9.125 of its municipal code. ${ }^{99}$ The ordinance allows police officers to issue a trespass warning for any conduct that is "dangerous, unsafe, illegal, or unreasonably disruptive to other uses of public property." 100 Such behavior could include using electronic or communicative devices in a manner that is unreasonably disruptive to others, wearing insufficient clothing for the location, or even having body odor that is unreasonably offensive to others. ${ }^{101}$ These trespass warnings allow police to banish individuals from an area for up to seven days after the first warning, and then up to a year for any subsequent warnings. ${ }^{102}$ The individual receiving the warning need not be charged, tried, or convicted of any crime. ${ }^{103}$

Public response to the new ordinance was overwhelmingly negative. Mike Alben, a pastor for Burien Evangelical Church who invited roughly a dozen homeless citizens to sleep on church property, criticized the treatment of homeless individuals as affording them "little to no dignity." 104 The American Civil Liberties Union sent a letter to the City of Burien urging them to repeal the law for being "counterproductive as a matter of policy and unconstitutional.", Burien City Manager Kamuron Gurol responded eight days later in a statement that defended the

\footnotetext{
98 8.20.010 Nuisances Defined; 7.04.020 Pedestrian Interference; and 7.13.040 Unlawful Bus Conduct.

${ }^{99} \mathrm{BMC}$ 9.125.020. Full text of the ordinance is available at http://www.codepublishing.com/wa/burien/html/Burien09/Burien09125.html\#9.125.

${ }^{100}$ BMC 9.125.020(1).

${ }^{101}$ BMC 9.125.015.

102 BMC 9.125.020(4).

103 BMC 9.125.020(3).

${ }^{104}$ KIRO 7 Eyewitness News, Burien's Trespass Ordinance to Address Disturbances in Public Spaces, KIROTV.COM (Aug. 23, 2014), http://www.kirotv.com/news/news/buriens-trespass-ordinance-addressdisturbances-pu/ng74s/.

${ }^{105}$ Letter from Jennifer Shaw to Lucy Krakowiak and the Burien City Council (Oct. 6, 2014), available at https://aclu-wa.org/news/aclu-urges-burien-repeal-unconstitutional-law-targeting-homeless.
} 
constitutionality of the ordinance and pointed to the guaranteed right of appeal as "an essential feature of the Ordinance."106 However, (1) the appeals process is available only to individuals receiving a trespass warning for a period longer than seven days; (2) the request for an appeal must be made in writing with a copy of the warning delivered to the City's Legal Department; and (3) a sworn report or declaration from the officer who issued the trespass warning will suffice, without further evidentiary foundation, as prima facie evidence that the individual committed the violation as described. ${ }^{107}$ These critical components of Chapter 9.125 limit the ability of homeless individuals to protect themselves from the repercussions of the ordinance.

Since the public backlash, the City of Burien repealed the portion of Chapter 9.125 dealing with body odor; however, the other provisions of the ordinance, including the stringent appeals process requirements, remain unchanged at the time of this writing. ${ }^{108}$

\section{i. Citations}

Aside from the controversies surrounding the new Chapter 9.125, Burien's data on existing laws showed a typical approach to enforcement of these ordinances. During the requested five year period, Burien issued a total of 215 citations. Of those, Burien police issued citations for obstruction of sidewalks or public places (151 or $70 \%$ ) more than any other. ${ }^{109}$ Burien reported additional citations for living or sleeping in vehicles (61 or 29\%) and aggressive panhandling ( 3 or $1 \%) .{ }^{110}$ No citations were issued for the remaining six criminalization ordinances and, at the time of this writing, no records yet exist for trespass warnings under Chapter 9.125. ${ }^{111}$

\section{ii. Case Dispositions and Sentencing}

Information regarding the disposition of citations was particularly scarce. The court simply noted that the majority of the citations (179 or $83 \%)$ were resolved. ${ }^{112}$ None of the citations led to the issuance of a warrant, and only two individuals received any sentences of jail time.

Burien's approach to punishment is far more worrisome. Within the criminalization ordinances themselves, punishments range from fines of $\$ 50$ up to penalties of $\$ 250$ for each

\footnotetext{
${ }^{106}$ Statement from the Burien City Manager Regarding its Trespass Ordinance, CITY OF BURIEN, http://burienwa.gov/DocumentCenter/View/5174 (last visited Apr. 1, 2015).

${ }^{107}$ BMC 9.125.020(7) and (8).

${ }^{108}$ Kipp Robertson, Advocates Still Raising Stink Over Burien Law, Say it Targets Homeless, MYNoRTHWEST.COM (Feb. 24, 2015), http://mynorthwest.com/11/2715929/Advocates-still-raising-stink-over-Burien-law-say-it-targetshomeless.

${ }^{109}$ As a note, the City of Burien stated that it does not issue citations for BMC 8.45.020 (obstruction of sidewalks or public places) but instead issues "notices of violation." Because the effect here appears to be the same, and for purposes of consistency, this sub-section will continue to refer to these notices as citations. In addition, Burien referred Practicum researchers to the King County District Court, South Division, which (through an interlocal agreement) handles all of Burien's local ordinance adjudications.

${ }_{110}$ BMC 7.30.110 and 9.80.400.

${ }^{111}$ Additional records may be requested from the Burien Police Department as part of future research.

112151 "notices of violation" were resolved with 10 outstanding. Of the remaining 54 citations, 28 were resolved and 26 were outstanding.
} 
violation. ${ }^{113}$ However, all of these specific penalty provisions are arguably meaningless. Under the general provisions of Burien's municipal code, the city "shall have discretionary authority to enforce a violation as either a civil infraction ... or as a criminal misdemeanor . ..."114 Thus, the city could pursue enforcement of any ordinance as a criminal misdemeanor, and the courts would be empowered to impose a sentence including 90 days in jail and \$1,000 in fines.

And of course, the notable punishment outlier remains the new Chapter 9.125. As discussed, this ordinance allows a police officer to banish an individual from a public place without the individual being charged, tried, or convicted of any crime or infraction. Because of how the ordinance is written, Chapter 9.125 could be used to prevent a wide variety of behaviors, including obstruction of sidewalks, bathing in public waters, urinating/defecating in public, and creating a nuisance through body odor. Thus, police officers have the power to both cite individuals for this behavior and banish them from the area. Without more specific data on the enforcement of Chapter 9.125, researchers are unable to determine shed light on how enforcement practices relate to existing legal and policy concerns about Burien's controversial law.

\section{iii. Overlapping Ordinance Concerns}

Burien contains numerous overlapping ordinances, covering such categories as obstruction of sidewalks, bathing in public waters, urinating/defecating in public, and creating body odor. While all of these ordinances contain consistent penalties, ${ }^{115}$ the general provision above allows for discriminatory enforcement under any or all of them.

Burien has codified expansive measures aimed at removing visible poverty, to the detriment of due process and equal protection. Although Burien's citation numbers are not extraordinary, the mechanisms in place for discriminatory enforcement are staggering. The general punishment provisions allow for limitless discretion in applying civil or criminal penalties for any violation. In addition, the controversial Chapter 9.125 allows police officers to banish an individual from a public place without any due process. The possibilities for discriminatory enforcement placed Burien under heavy scrutiny by the local community and homeless rights advocates statewide.

\footnotetext{
${ }^{113} \mathrm{BMC}$ 10.15.080 and BMC 1.15.120(2), respectively.

${ }^{114}$ BMC 1.15.080(1).

${ }^{115}$ Ordinances for obstruction of sidewalks or public places and urinating in public carried misdemeanor penalties; ordinances dealing with bathing in public waters are classified as Class 1 infractions with a penalty up to $\$ 250$.
} 


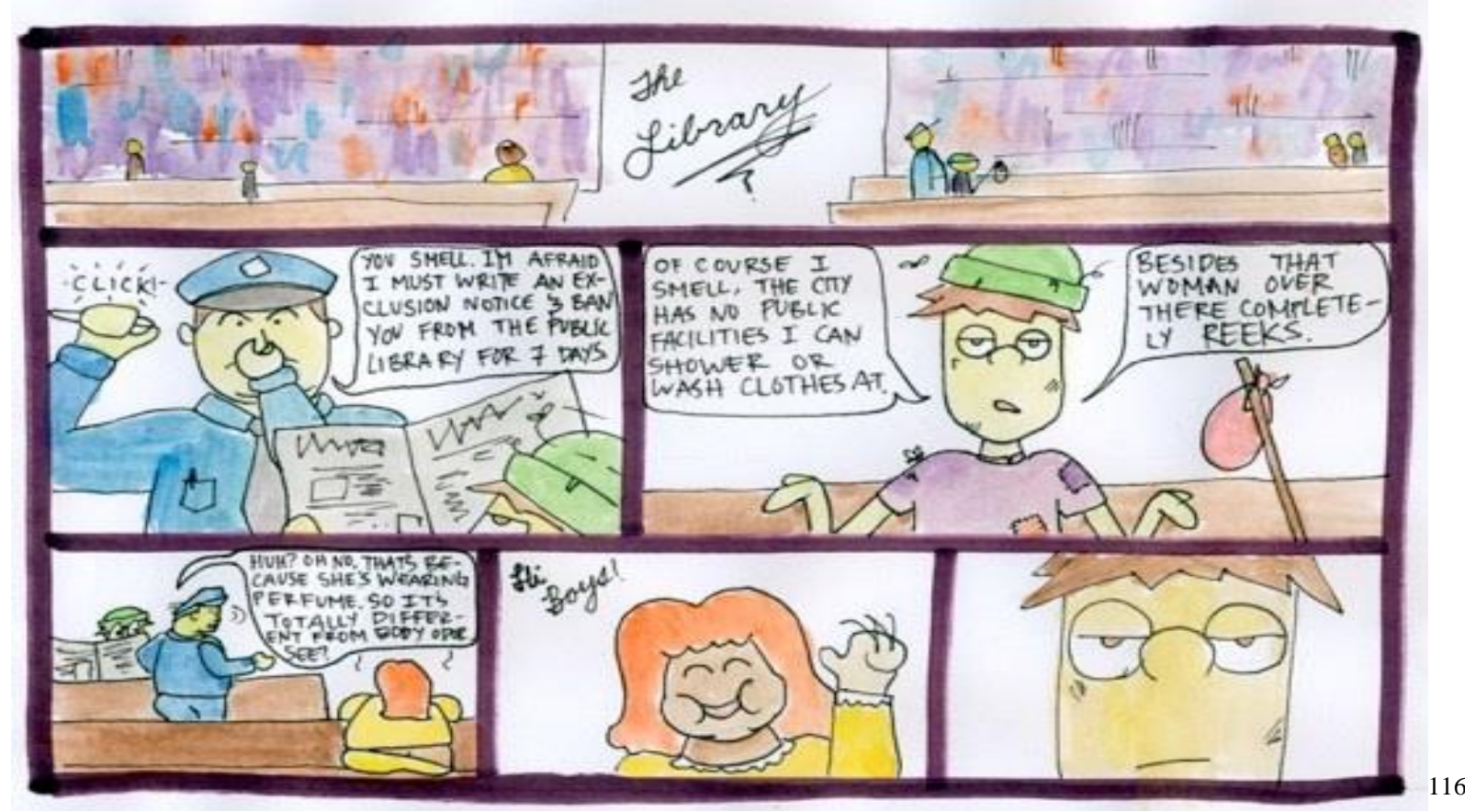

\section{Auburn}

Population (in 2010):

Persons Below Poverty Level:

Total Housing Units:

Land Area in Square Miles:

Total Number of Business Firms:

Median Household Income:
70,180

$14.9 \%$

27,834

29.62

5,068

$\$ 39,208$

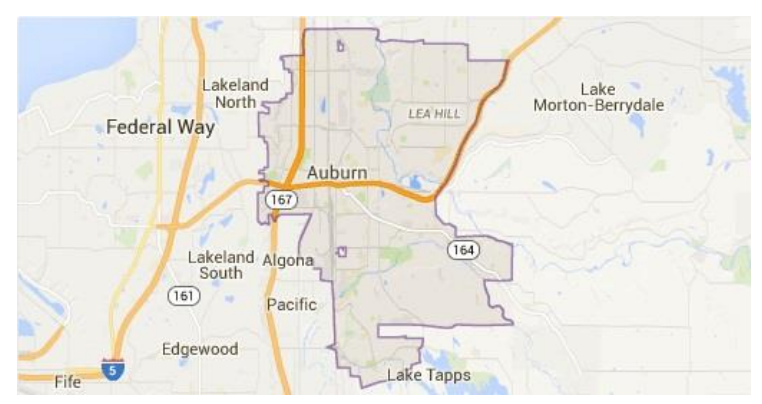

Located between Seattle and Tacoma in the shadow of Mt. Rainier, Auburn boasts a robust outdoor lifestyle. The city has access to the White and Green River trails, three golf courses, and approximately 30 parks of varying sizes. ${ }^{117}$ Auburn is also home to the Muckleshoot Indian Tribe. According to census data, only $14.9 \%$ of residents are below the poverty level; other data suggests Auburn's poverty rate is greater than $30 \% .{ }^{118}$ Unfortunately, Auburn has two other notable qualities: it has the highest number of homeless criminalization ordinances out of all 72 surveyed municipalities, and it provided the least amount of information of any case study city.

\footnotetext{
${ }^{116}$ Comic based on Deborah Horne, New Ordinance Allows Police to Ban Smelly People from City Buildings, KIRO 7 (Sept. 15, 2014), http://www.kirotv.com/news/news/new-ordinance-allows-police-ban-smelly-peoplecity/nhNK8/.

117 About Auburn, CITY OF AUBURN, http://www.auburnwa.gov/about.htm (last visited Dec. 4, 2014).

${ }^{118}$ King County 2010-2014 Consolidated Housing \& Development Program, 2009 Needs Assessment 11 (2009), available at www.kingcounty.gov/ /media/socialServices/housing/documents/2010_12_Consol_Plan_Append_A.ashx?la=en.
} 


\section{i. Citations}

Although Auburn has enacted the highest total number of criminalization ordinances, Auburn has the lowest number of citations of the seven case study cities (203 total citations). Of these reported citations, the most frequently cited behavior was obstruction of sidewalks/public places $(125$ or $62 \%) .{ }^{119}$ The other reported citations were for aggressive panhandling (77 or $38 \%)^{120}$ and loitering city-wide (1 or less than $\left.1 \%\right){ }^{121}$

Auburn's municipal code contains numerous overlapping ordinances, covering behaviors such as camping in public places, ${ }^{122}$ obstructing pedestrian traffic, ${ }^{123}$ and urinating/defecating in public. ${ }^{124}$ All of the ordinances under these categories are classified as misdemeanors. Auburn also has overlapping ordinances for scavenging, but these overlapping ordinances also provide for similar penalties between them (civil fines up to \$250). ${ }^{125}$

\section{ii. Case Dispositions and Sentencing}

Regrettably, Auburn did not provide any information relating to the disposition and sentencing of citations.

\section{Pasco}

Population (in 2010):

59,781

Persons Below Poverty Level: $\quad 23.0 \%$

Total Housing Units:

18,782

Land Area in Square Miles:

30.50

Total Number of Business Firms: $\quad 3,150$

Median Household Income:

$\$ 49,220$

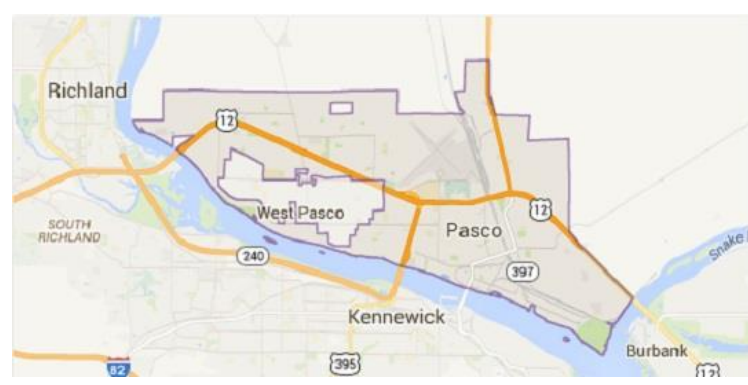

Pasco is one of three cities making up the Tri-Cities metropolitan region of southeast Washington, along with Kennewick and Richland. The city has experienced rapid residential growth over the past fifteen years, with a 2014 population estimate that is over double the population in 2000. ${ }^{126}$ Unfortunately, Pasco also has the highest percentage of people below the poverty level out of all seven case study cities.

\section{i. Citations}

Pasco is notable for having the lowest total number of reported citations. During the requested five year period, Pasco issued 93 citations. Of those, Pasco police issued most of the

\footnotetext{
${ }^{119}$ AMC 9.78.010.

${ }^{120}$ AMC 9.08.010.

121 AMC 9.50.020.

${ }^{122}$ AMC 9.100.500 and 2.22.210.

${ }^{123}$ AMC 9.08.010, 9.50.020, 9.62.900, 9.78.010, and 9.100.500.

${ }^{124}$ AMC 9.78.010 and 9.100.500.

${ }^{125}$ AMC 8.08.100 and 8.16.031.

${ }^{126}$ History and Highlights of Pasco, CITY OF PASCO, http://www.pasco-wa.gov/428/History-and-Highlights-ofPasco (last visited Mar. 31, 2014).
} 
citations for urination or defecation in public (54 or 59\%). After that, Pascoe reported citations only for loitering in particular public places (32 or 34\%), begging in particular public places (6 or $6 \%$ ), and sitting/lying in particular public places $(1$ or $1 \%) .{ }^{127}$

\section{ii. Case Dispositions and Sentencing}

Unfortunately, Pasco did not provide any additional information responsive to HRAP researchers' requests. ${ }^{128}$

\section{iii. Overlapping Ordinance Concerns}

Pasco has three behaviors criminalized by overlapping ordinances: begging in public, ${ }^{129}$ scavenging, ${ }^{130}$ and obstruction of sidewalks/public places. ${ }^{131}$ Both ordinances for begging in public punished the behavior as a misdemeanor. The two scavenging ordinances contained different penalties, but were associated with different circumstances: it is a misdemeanor to scavenge solid waste from containers in general, yet scavenging at a bus station is merely a civil infraction. ${ }^{132}$ Pasco did not report any citations under either scavenging ordinance in the past five years.

Pasco's two obstruction ordinances also provided for different penalties. ${ }^{133}$ Under the direct obstruction ordinance, sitting or lying down on the sidewalk is punishable as a misdemeanor. Under the nuisance ordinance, the same behavior is punishable as a civil infraction. Pasco reported one citation issued under the sit/lie ordinance, and no citations under the nuisance ordinance. Although the data did not reveal discriminatory enforcement, the ordinances as written still allow for the possibility.

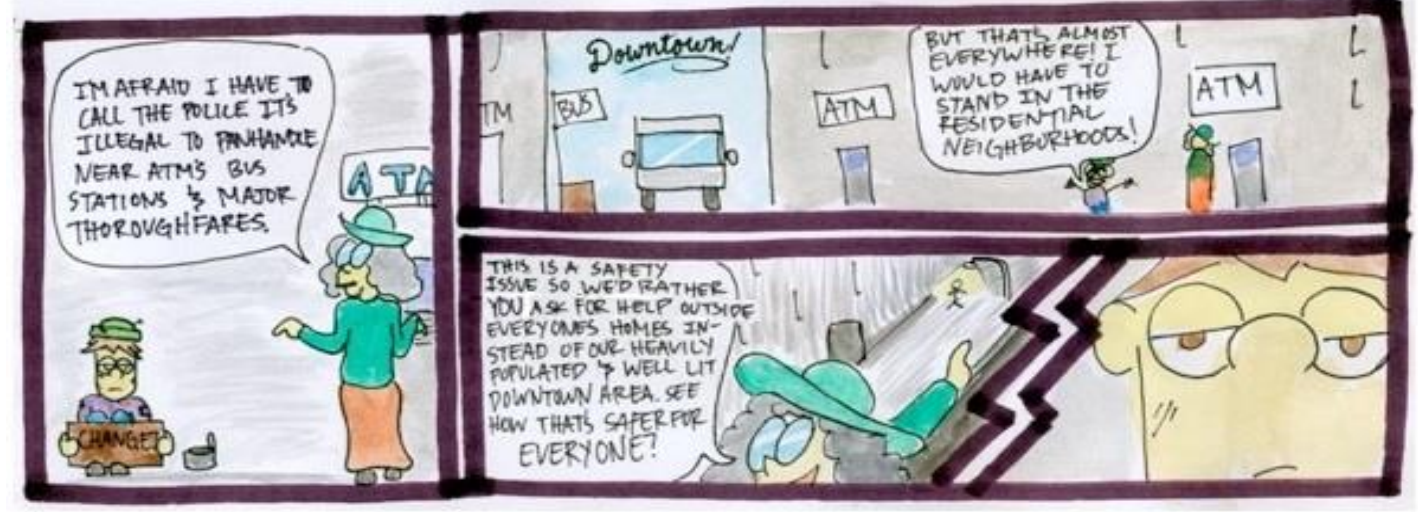

\footnotetext{
${ }^{127}$ The single citation for sitting/lying in public places stems from a compound ordinance that prohibits another type of conduct: sleeping in particular public places. It is unclear which category this particular citation belongs under.

${ }^{128}$ Pasco Municipal Court could not provide additional information outside of its Judicial Information System (JIS) database available for public use in the King County District Court. The system was not user-friendly.

${ }^{129}$ PMC 9.14.020 and 9.44.060.

${ }^{130} \mathrm{PMC}$ 6.04.270 and 9.64.120.

${ }^{131}$ PMC 9.44.010 and 9.60.020.

${ }^{132}$ Pasco Municipal Codes 9.64.120 and 6.04.270.

133 9.60.20 Nuisances Defined and 9.44.010 Unlawful Street or Sidewalk Interference.

${ }^{134}$ Comic based on Josh Farley, Bremerton Council Passes Panhandling Ordinance, KITSAP SUN (Nov. 6, 2014), http://www.kitsapsun.com/news/local-news/panhandling_vote_110714_21089784.
} 


\section{CONCLUSIONS \& RECOMMENDATIONS}

Across Washington, cities are embracing criminalization as a solution to the problem of homelessness and visible poverty. The best predictor of ordinance enactment is time. Since 2000 , criminalization ordinances have been enacted at a rapidly growing rate without any indication of slowing down. Additionally, income disparity levels predict aggressive enforcement of a city's criminalization ordinances. As the income disparity gap widens, visible poverty increases. The presence of visible poverty may trigger policy efforts to "clean up the streets." Because cities are no likely to abandon enactment efforts and income disparity continues to rise across Washington, ${ }^{135}$ the criminalization of homelessness is almost certain to get worse.

This brief does not purport to solve the complex problem of homelessness. Instead, the specific focus of this brief is to examine the scope and extent of the criminalization of homelessness throughout the state of Washington based on available data. This report shows: (1) Washington cities are increasingly criminalizing homelessness; (2) these laws frequently target necessary life-sustaining activities, even though people without shelter have no reasonable alternative but to conduct these activities in public; (3) the enforcement of these laws raises legal and policy concerns, such as inconsistent or selective citation and sentencing practices; (4) the enactment of overlapping and compound ordinances raises constitutional equal protection and due process concerns; (5) the link between income disparity and enforcement of these ordinances should prompt lawmakers to re-consider the societal impact of homeless criminalization; and (6) the limited and inconsistent access to data impedes researchers from demonstrating the full extent of homeless criminalization.

The most obvious way to address the problem of anti-homeless regulations is to repeal laws that criminalize life-sustaining activities or disproportionately target homeless or visibly poor individuals. To paraphrase Chief Justice John Roberts, the way to stop discrimination on the basis of homelessness is to stop discriminating on the basis of homelessness. ${ }^{136}$ Cities rely on criminalization to resolve the problems associated with visible poverty. However, criminalization is a broken system that fails to protect the rights and dignities of homeless individuals. Without reliance on criminalization, cities will be compelled to address homelessness directly through systemic social policy changes that respect the inherent humanity of the homeless population.

For the short term, however, there are a number of ways cities can provide both fairer treatment of homeless people and greater transparency for researchers. Local jurisdictions should take care when drafting ordinances to ensure the laws are clear and targeted at truly criminal conduct. To that point, jurisdictions should also avoid writing compound ordinances or

\footnotetext{
${ }^{135}$ Jennifer Romich, Poverty, Income Inequality Increase in Washington State, UWTODAY (Sept. 18, 2014), http://www.washington.edu/news/2014/09/18/poverty-income-inequality-increase-in-washington-state/.

${ }^{136}$ Paraphrased from Chief Justice Roberts's famous line, "[ $\left.\mathrm{t}\right]$ he way to stop discrimination on the basis of race is to stop discriminating on the basis of race." Parents Involved In Community Schools v. Seattle School District No. 1, 551 U.S. 701 (2007).
} 
allowing the passage of unnecessary overlapping ordinances. Jurisdictions should also consider whether the conduct is already criminalized through other facially neutral laws. Additionally, cities should endeavor to make their municipal codes easier to navigate and search. And finally, municipal courts in every jurisdiction should be provided with modern technology and software so that basic enforcement and demographic data is easily accessible to the public.

While it may seem a matter of common sense, municipalities should take great care in drafting their ordinances. Some ordinances have ambiguous terms that lead to discriminatory enforcement when left open to interpretation. Additionally, municipalities should include a statement of purpose exempting acts of genuine necessity and survival so that the ordinances are used to punish criminally unlawful conduct. These recommendations would help address the problem of ordinances criminalizing life-sustaining activities while remaining facially neutral. Cities would thus provide much-needed clarity to their municipal codes in ways that better serve their entire populations.

Furthermore, both overlapping and compound ordinances create hurdles for the city and researchers alike. As suggested by the enactment data above, overlapping ordinances allow for officers to apply different punishment schemes to different individuals being cited for the same conduct. This phenomenon opens the door to potential constitutional violations, such as due process and equal protection. Compound ordinances should also be eliminated, though for different reasons. These convoluted ordinances require researchers to effectively guess at the actual conduct an individual was cited for when the case was filed under a single ordinance with several applicable conducts. Without being able to distinguish what conduct led to a citation, it is very difficult for any interested parties to pinpoint what behavior is truly at issue. ${ }^{137}$

Finally, while some municipalities used online municipal code databases very effectively, several others had broken search functions or simply linked to PDF files. Despite the limited resources of municipal governments, maintaining an open and accessible municipal code is crucial. Legal practitioners, pro se defendants, police officers, and city advisors will all benefit from a city code that is easier to navigate. And for interested parties looking into the state of the law, a user-friendly system will lead to better data, and thus more reliable results. ${ }^{138}$

All these recommendations are vital to better understanding and addressing the moral, legal, and economic consequences of persecuting one of the most vulnerable segments of society. Even the most modest improvements suggested in this brief can help illuminate the extent of criminalization throughout Washington. To get at the heart of the problem, however, cities must stop relying on the criminalization of visible poverty as a solution to homelessness.

\footnotetext{
${ }^{137}$ For instance, if an ordinance criminalizes both begging at intersections and aggressive begging, the citation number will suggest a citation issued for both forms of conduct. This makes it functionally impossible to bolster programs intended to target the at issue conduct, whichever it may be.

${ }^{138}$ For individuals interested in performing similar research in your own state, a discussion of the research process is provided in Appendix V.
} 


\section{APPENDIX}

\section{I-A. Phase I Request Letter}

[Month] [Day], [Year]

[Served Entity]

Attn: [Recipient name]

[Title]

[Address 1]

[Address 2]

Via [mail or Email]: [email address if applicable]

RE: Public Records Act Request - Citation Information for [City] Municipal Codes

To Whom It May Concern:

I am requesting that the records described below be made available for inspection, pursuant to the Washington Public Records Act (RCW §42.56 et seq.). In accordance with RCW 42.56.520, you must, within five business days of receipt of this request, respond and let me know the status of the request and how soon you will be able to produce all discoverable records.

I am requesting certain information (see specific questions below) pertaining to citations issued due to violations of the following [City] Municipal Codes:

[Code section 1]

[Code section 2]

[Code section 3]

[Repeat as necessary]

Specifically, I am requesting all relevant records related to the following questions for the time period between January 1, 2009, and December 31, 2013:

1) How many total citations were issued under the city codes specified above?

2) How many citations were issued per each separate city code specified above?

3) How many of the citations were issued to people who are homeless/transient?

4) Of the citations issued to homeless/transient individuals, how many citations were issued per each separate city code specific above?

5) How many of these citations were resolved, or how many are still outstanding?

6) What are the consequent fines that result from any citation issued pursuant to violations of the city codes specified above?

7) How many people spent time in custody as a result of these citations and how much time did they spend in custody? 
8) How many cases led to the issuance of a warrant? How many were brought to the station and/or sent to jail?

9) What are the consequent fines/additional charges that are a result of a failure to appear for these citations?

At this time, please refrain from making copies of any responsive documents. Instead, please contact me to schedule a time for me or my representatives to inspect the documents requested above, at which time we will select those documents we would like copied. You may send any written responses to this request to:

[Supervisor]

[Institution]

[Address 1]

[Address 2]

If any documents are withheld in whole or in part, please specify the reason for withholding such document or any portion thereof. For any document withheld in its entirety, please state the name and date of the document as well as the number of pages within the document. To the extent that portions of the request are specifically exempted from disclosure, please provide all non-exempt portions as allowed for under the Washington Public Records Act. To the extent that any portion of the requested records contain classified information, please redact such information and furnish the requested records.

We very much appreciate your attention to this request. If you would like to contact me with questions or concerns about the requested information please feel free to do so as I am more than happy to clarify in any way I can. Please contact me with any questions at [Supervisor mail] or at [Supervisor phone].

I look forward to hearing from you within five business days. Thank you for your assistance!

Very truly yours,

[Name]

[Title]

[Institution]

[Address 1]

[Address 2] 


\section{I-B. Phase II Request Letter}

[Month] [Day], [Year]

[Served Entity]

Attn: [Recipient name]

[Title]

[Address 1]

[Address 2]

\section{Via [mail or Email]: [email address if applicable]}

RE: Public Records Act Request - Citation Information for [City] Municipal Codes

To Whom It May Concern:

Thank you for the excellent information you have provided pursuant to our public records request. After reviewing the responsive data, we would like to request additional information pursuant to the Washington Public Records Act (RCW §42.56 et seq.) regarding the [City] Municipal Code citations issued between January 1, 2009, through December 31, 2013, under the following ordinances:

[Code section 1]

[Code section 2]

[Code section 3]

[Repeat as necessary]

Specifically, we are requesting all relevant records related to the following questions:

1) What is the cost per day (on average) to keep an individual in police custody?

2) What is the average "booking cost" associated with the violation of ordinances listed above?

In addition, for the citations of each ordinance listed above:

3) What was the age of each defendant?

4) How many defendants were male and how many were female?

5) What was the ethnicity of each defendant?

6) How many defendants had a physical disability?

7) How many defendants had a mental health disability?

8) How many defendants identified as homosexual, bisexual, or transgender?

9) How many defendants were U.S. citizens?

10) How many defendants were legal immigrants?

11) How many defendants were illegal immigrants? 
12) How many defendants identified as veterans?

13) How many defendants were identified as having substance abuse issues?

14) For the citations involving a disability or substance abuse, how was this determined?

(For example, did the officer determine this at arrest, did the defendant identify as having a disability, etc.?)

15) How many defendants were receiving mental health services at the time of the citation?

16) How many defendants retained an attorney?

17) How many defendants retained a public defender?

Please note that this data does not need to be separated by ordinance - total numbers will suffice. If the City of [City] does not track the data related to any of the requests above, please let us know.

At this time, please refrain from making copies of any responsive documents. Instead, please contact me to schedule a time for me or my representatives to inspect the documents requested above, at which time we will select those documents we would like copied. You may send any written responses to this request to:

[Supervisor]

[Institution]

[Address 1]

[Address 2]

If any documents are withheld in whole or in part, please specify the reason for withholding such document or any portion thereof. For any document withheld in its entirety, please state the name and date of the document as well as the number of pages within the document. To the extent that portions of the request are specifically exempted from disclosure, please provide all non-exempt portions as allowed for under the Washington Public Records Act. To the extent that any portion of the requested records contain classified information, please redact such information and furnish the requested records.

We very much appreciate your attention to this request. If you would like to contact me with questions or concerns about the requested information please feel free to do so as I am more than happy to clarify in any way I can. Please contact me with any questions at [Supervisor email] or at [Supervisor phone].

I look forward to hearing from you within five business days. Thank you for your assistance!

Very truly yours,

[Name]

[Title]

[Institution]

[Address 1]

[Address 2] 


\section{Examples of Homeless Criminalization Ordinances (By Category of Behavior)}

A. Sleeping in public city-wide

A. "Camping" means the use of park land or other publicly owned property for living accommodation purposes including but not limited to any of the following:

1. Sleeping activities;

2. Making preparations to sleep;

3. Laying down of bedding for the purpose of sleeping;

4. Storing personal belongings;

5. Erecting any tent, tarpaulin, shelter, or other structure that would permit one to sleep overnight;

6. Using a motor vehicle for the purposes of sleeping.

\section{Issaquah Municipal Code 9.26.010 Camping, defined.}

It is unlawful for any person to engage in camping in any park or playfield owned by the City, or on any sidewalk, street, alley, lane, public right-of-way, or under any bridge or viaduct, or in any other public place to which the general public has access. (Ord. $2261 \S$ $1,2000)$.

\section{Issaquah Municipal Code 9.26.030 Camping prohibited.}

\section{B. Sleeping in particular public places}

It shall be unlawful within the area of the City of Pasco bordered by the railroad tracks on the east, 14th Avenue on the west, Bonneville street on the north and "A" Street on the south, for any person to sit, lay, or sleep on any public right-of-way except for medical emergency, in the furtherance of work or repair to the public right-of-way or of any property or building immediately adjacent thereto or in furtherance of a special permit issued by the City under some other chapter of this code. A violation of this section is a misdemeanor. (Ord. 3491 Sec. 2, 2001; Ord. 2561 Sec. 1, 1985)

\section{Pasco Municipal Code 9.44.030 Sitting, Laying, or Sleeping on Right-of-Way}

\section{Prohibited}




\section{Camping in public city-wide}

A. It shall be unlawful for any person to camp, occupy camp facilities for purposes of habitation, or use camp paraphernalia in the following areas, except as otherwise provided by ordinance or as permitted pursuant to Section 8.22.070 of this ordinance:

1. any park;

2. any street; or

3. any publicly owned or maintained parking lot or other publicly owned or maintained area, improved or unimproved.

$\cdots$

\section{Vancouver Municipal Code 8.22.040 Unlawful camping.}

D. Camping in particular public places

No person shall camp in any park area including any park parking lot. [Ord. $475 \S 2$, 2007]

\section{Burien Municipal Code 7.30.110 Camping.}

\section{E. Sitting/lying in particular public places}

(1) Prohibition. No person shall sit or lie down upon a public sidewalk, or upon a blanket, chair, stool or other object placed upon a public sidewalk, within the city of Marysville during the hours between 6:00 a.m. and 12:00 midnight.

(2) Exceptions. The prohibition in subsection (1) of this section shall not apply to any person:

(a) Sitting or lying down on a public sidewalk due to a medical emergency;

(b) Who, as a result of a disability, utilizes a wheelchair, walker or similar device to move about the public sidewalk;

(c) Operating or patronizing a commercial establishment conducted on the public sidewalk pursuant to a street use permit; or a person participating in or attending a parade, festival, performance, rally, demonstration, meeting or similar event conducted on the public sidewalk pursuant to a street use or other applicable permit;

(d) Sitting on a chair or bench located on the public sidewalk which is supplied by a public agency or by the abutting private property owner; 
(e) Sitting on a public sidewalk within a bus stop zone while waiting for public or private transportation.

Nothing in any of these exceptions shall be construed to permit any conduct which is prohibited by Chapter 6.37 MMC, Pedestrian Interference.

(3) No person shall be cited under this section unless the person engages in conduct prohibited by this section after having been notified by a law enforcement officer that the conduct violates this section. (Ord. $2157 \S 1,1997$ ).

\section{Marysville Municipal Code 12.22.010 Sitting or lying down on public sidewalks in downtown commercial zones.}

\section{$\underline{\text { F. Lodging, living, or sleeping in vehicles }}$}

B. It shall be unlawful for any person to occupy a vehicle for the purpose of camping while that vehicle is parked in the following areas, except as otherwise provided by ordinance or as permitted pursuant to Section 8.22.070 of this ordinance:

1. any park;

2. any street; or

3. any publicly owned or maintained parking lot or other publicly owned or maintained area, improved or unimproved.

\section{Vancouver Municipal Code 8.22.040 Unlawful camping.}

\section{G. Loitering/loafing/ vagrancy city-wide}

A. It is unlawful for any person to loiter, loaf, wander, stand or remain idle either alone and/or in consort with others in a public place in such a manner so as to:

1. Obstruct any public street, public highway, public sidewalk or any other public place or building by hindering or impeding or tending to hinder or impede the free and uninterrupted passage of vehicles, traffic or pedestrians;

2. Commit in or upon any public street, public highway, public sidewalk or any other public place or building any act or thing which is an obstruction or interference to the free and uninterrupted use of property or with any business lawfully conducted by anyone in or upon or facing or fronting on any such public street, public highway, public sidewalk or any other public place or building, all of which prevent the free and uninterrupted ingress, egress and regress, therein, thereon and thereto. 
B. When any person causes or commits any of the conditions enumerated in subsection A of this section, a police officer or any law enforcement officer shall order that person to stop causing or committing such conditions and to move on or disperse. Any person who fails or refuses to obey such orders is guilty of a violation of this chapter. (Ord. $5682 \S 1$, 2002.)

\section{Auburn Municipal Code 9.50.020 Order to disperse.}

\section{$\underline{\text { H. Loitering/loafing in particular public places }}$}

A. It is unlawful to camp in a park except at places set aside for such purpose by the city and so designated by signs.

B. It is unlawful to remain, stay or loiter in a park between the hours of 9:00 p.m. and 6:00 a.m. (Ord. 13-05 § 4, 2013; 1967 code $\$ 8.40 .090$ )

\section{East Wenatchee Municipal Code Section 12.12.090 Camping regulations.}

\section{Obstruction of sidewalks/public places}

A. The following definitions apply in this section:

$\ldots$

4. "Obstruct pedestrian or vehicular traffic" means to walk, stand, sit, lie, or place an object in such a manner as to block passage by another person or a vehicle, or to require another person or a driver of a vehicle to take evasive action to avoid physical contact. Acts authorized as an exercise of one's constitutional right to picket or to legally protest, and acts authorized by a permit issued pursuant to the Street Use Ordinance, Chapters 15.02 through 15.50 of the Seattle Municipal Code, shall not constitute obstruction of pedestrian or vehicular traffic.

5. "Public place" means an area generally visible to public view and includes alleys, bridges, buildings, driveways, parking lots, parks, plazas, sidewalks and streets open to the general public, including those that serve food or drink or provide entertainment, and the doorways and entrances to buildings or dwellings and the grounds enclosing them.

B. A person is guilty of pedestrian interference if, in a public place, he or she intentionally:

1. Obstructs pedestrian or vehicular traffic; or

2. Aggressively begs.

C. Pedestrian interference is a misdemeanor. 


\section{Seattle Municipal Code 12A.12.015 Pedestrian interference.}

\section{$\underline{\text { J. Closure of particular public places }}$}

No Washington Ordinances could be located for this category.

\section{$\underline{\text { K. Other restrictions on "vagrants" }}$}

A. Any person who wanders or prowls in a place, at a time, or in a manner, and under circumstances which manifest an unlawful purpose or which warrant alarm for the safety of persons or property in the vicinity is declared to be a vagrant and is guilty of a misdemeanor.

B. Among the circumstances which may be considered as manifesting an unlawful purpose or warranting alarm for the safety of persons or property, for the purposes of this section, include but are not limited to the following:

1. Flight by a person upon the appearance of a police officer;

2. Refusal of a person to identify himself to a police officer;

3. Attempt by a person to conceal himself or any object from a police officer.

C. No arrest shall be made under this section, nor shall any person be convicted of an offense under this section, unless the police officer first advises such person of his Fifth Amendment constitutional rights and then affords an opportunity for a person suspected of violating this section to dispel any alarm which would otherwise be warranted by requesting such person to identify himself and explain his presence and conduct, unless flight by the suspected violator or other circumstances make it impractical for the police officer to afford such an opportunity.

D. No person shall be convicted of an offense under this section if it appears at trial that the explanation given by the suspected violator was true and, if believed by the police officer at the time, would have dispelled the alarm or suspicion of unlawful purpose. (Ord. 628, 1976)

\section{Monroe Municipal Code 9.08.080 Wandering or prowling under circumstances manifesting unlawful purpose.}

$\underline{\text { L. Explicit provisions allowing for trespass warning to be given (e.g., St. Petersburg, FL) }}$

A. Immediate Expulsion: Any person violating a rule or provision of this Chapter or any federal, state or local law may be ordered by a commissioned peace officer to leave the Transit Center immediately. 
B. Second Expulsion: Any person violating a rule or provision of this Chapter or any federal, state or local law and who has been the subject of a prior expulsion within the immediately preceding three (3) days may be ordered by a commissioned peace officer to leave the Transit Center immediately and will be subject to expulsion for up to seven (7) calendar days.

C. Expulsion Up To One (1) Year: Any person violating a rule or provision of this Chapter or any federal, state or local law and (1) who has been the subject of two prior expulsions within the immediately preceding thirty (30) days, or (2) who has been expelled from the Transit Center three (3) or more times in any 90-day period may be ordered by a commissioned peace officer to leave the Transit Center immediately AND will be subject to expulsion for up to one (1) year.

D. Failure to comply with any expulsion order shall be grounds for prosecution for criminal trespass. (Ord. 5587, 12-13-10; Ord. 5598, 4-25-11)

\section{Renton Municipal Code 6-31-3 Expulsion}

\section{$\underline{\text { M. Enforcement of criminal trespass provisions in public places (e.g., Portland, ME) }}$}

A. It is unlawful for any person to:

1. Enter or remain in any park during the period covered by an expulsion notice pursuant to RMC 6-30-2; or

2. Enter, remain in, or be present within the premises of a park during hours that the park is not open to the public.

B. It is not a defense to the crime of trespass in parks:

1. That the underlying expulsion issued pursuant to this chapter is on appeal when the expelled person was apprehended, charged, or tried under this section; nor

2. That the expelled person entered or remained in the park pursuant to a permit that was issued either before or after the date of the expulsion notice.

C. Any person who violates the provisions of this chapter shall be guilty of a misdemeanor and may be punished by a fine in any sum not to exceed one thousand dollars $(\$ 1,000)$ or by imprisonment for a term not to exceed ninety (90) days, or by both such fine and imprisonment. (Ord. 5533, 3-15-10)

\section{Renton Municipal Code 6-30-5 Trespass in Parks - Definition - Penalties}




\section{$\underline{\text { N. Storing personal property in public places }}$}

Except as permitted by permit pursuant to KCC 8.09 .050 or as otherwise provided by ordinance, it shall be unlawful for any person to store personal property, including camp facilities and camp paraphernalia, in any park or other public place.

(Ord. No. 3516, § 1, 7-5-00)

\section{Kent Municipal Code 8.09.020 Unlawful storage of personal property in public places.}

O. Bathing in particular public waters

It is unlawful for any person to boat, fish, wade, swim, scuba dive, snorkel, or bathe in any park except in the places and at times designated by the director. (Ord. $6465 \S 1$, 2013.)

Auburn Municipal Code 2.22.150 Prohibitions as to boating, fishing, and swimming.

P. Urination/defecation in public

A. A person is guilty of urinating in public if he or she intentionally urinates or defecates in a public place, other than a washroom or toilet room, under circumstances where such act could be observed by any member of the public.

B. "Public place" as used in this Section 12A.10.100 has the meaning defined in Section 12A.10.010 A3.

C. Except as provided in subsection D, any person who violates this Section 12A.10.100 shall be guilty of a violation as defined in Section 12A.02.080

D. Any person who violates this section and previously has either violated this section or has failed to appear as directed when served with a citation and notice to appear for a violation of this section is guilty of a misdemeanor.

Ord. $116896 \S 1$, 1993: Ord. $109674 \S 10,1981$ : Ord. $108867 \S 1$ 1, 1980: Ord. $108814 \S$ 9, 1980: Ord. 102843 § 12A.12.140, 1973.

\section{Seattle Municipal Code 12A.10.100 Urinating in public.}

Q. Creating body odor or restricting access to those with body odor

(4) Behavior that is "unreasonably disruptive to other users" is behavior that is not constitutionally protected and that unreasonably interferes with others' use and 
enjoyment of publicly owned property. Behavior that is unreasonably disruptive to others includes, but is not limited to, any of the following:

(a) Use of unreasonably hostile or aggressive language or gestures; or

(b) Unreasonably loud vocal expression or unreasonably boisterous physical behavior; or

(c) Using electronic or other communication devices in a manner that is unreasonably disruptive to others; or

(d) Wearing insufficient clothing for the location's use (e.g., no top, no bottom, no shoes); or

(e) Bodily hygiene or scent that is unreasonably offensive to others; or

(f) Unreasonably interfering with the free passage of staff or patrons in or on public property; or

(g) Behavior that is unreasonably inconsistent with the normal use for which the publicly owned property was designed and intended to be used (e.g., bathing, shaving, or washing clothes in a public bathroom or skateboarding in a public parking area or plaza).

(5) Any constitutionally protected action or speech is excluded from the prohibited behavior listed in this section. [Ord. $606 \S 1,2014]$

\section{Burien Municipal Code 9.125.015 Definitions [Modified January, 2015]}

(1) Officers of the Burien police department shall be empowered to issue a trespass warning to any individual who violates any city ordinance, state statute, or government rule or regulation relating to conduct that is dangerous, unsafe, illegal, or unreasonably disruptive to other users of public property as defined in BMC 9.125.015, while such individual is on or within any city or other publicly owned facility, building, or outdoor area that is open to the general public, as more specifically set forth in BMC 9.125.010(3).

\subsubsection{Trespass warnings on city and other property generally open to the public}

\section{$\underline{\text { R. Rummaging/scavenging/dumpster diving }}$}

It is unlawful for any person, firm or corporation, other than the city, the city's recycling contractor, or a private disposal company franchised by the city, to scavenge, remove or collect any garbage or refuse after it has been set out by a customer for collection at the curbside or other approved location. (Ord. $2540 \S 1$, 2004; Ord. 1822 \$, 1991). 


\section{Marysville Municipal Code 7.08 .055 Scavenging prohibited.}

\section{$\underline{\text { S. Begging in public places city-wide }}$}

A. Soliciting for Private Needs - Prohibited. No person shall solicit contributions for himself in or upon any public street or public place in the City of Maple Valley. $\cdots$

\section{Maple Valley Municipal Code 5.05.080 Charitable solicitations.}

\section{$\underline{\text { T. Begging in particular public places }}$}

A. Solicitation Near Designated Locations and Facilities.

1. It is unlawful for any person to solicit another person within fifteen feet of:
a. An automated teller machine;
b. A self-service fuel pump;
c. A public transportation stop; or
d. Any parked vehicle as occupants of such vehicle enter or exit such vehicle.

2. It is unlawful for a person to solicit another person in any public transportation facility or vehicle.

$\cdots$

\section{Centralia Municipal Code 10.37.050 Place of solicitation.}

\section{U. Aggressive" panhandling}

A. The following definitions apply in this section:

1. "Aggressively beg" means to beg with the intent to intimidate another person into giving money or goods.

2. "Intimidate" means to engage in conduct which would make a reasonable person fearful or feel compelled.

3. "Beg" means to ask for money or goods as a charity, whether by words, bodily gestures, signs, or other means.

... 
B. A person is guilty of pedestrian interference if, in a public place, he or she intentionally:

1. Obstructs pedestrian or vehicular traffic; or

2. Aggressively begs.

C. Pedestrian interference is a misdemeanor.

Ord. $117104 \S 1,1994:$ Ord. $116897 \S 1,1993:$ Ord. $113697 \S 1,1987$.

\section{Seattle Municipal Code 12A.12.015 Pedestrian interference.}

$\underline{\text { V. Other begging/panhandling restrictions (i.e. street performers, washing cars/windshields, etc.) }}$

No person shall engage in any solicitation within the limits of the city without having first registered with the city clerk, by name, residence and business address, residence and business telephone number, the purpose of any proposed solicitation, and the name of any other person on behalf of whom any solicitation is to be made, for the purpose of aiding the city officials in referring and resolving complaints, if any. (Ord. $302 \S 4,1977$ )

\section{Mukilteo Municipal Code 9.54.030 Registration -Required.}

$\underline{\text { W. Food Sharing city-wide or in particular public places (i.e. bans) }}$

No Washington ordinances could be located for this category.

$\underline{X}$. Restrictions on food sharing (i.e. permit requirements, etc.)

No Washington ordinances could be located for this category.

\section{$\underline{\text { Y. Other/miscellaneous restrictions }}$}

(1) It is unlawful for any person to do any of the following acts, if a shopping cart has a permanently affixed sign as provided in subsection (2) of this section:

(A) To remove a shopping cart from the parking area of a retail establishment with the intent to deprive the owner of the shopping cart the use of the cart; or

(B) To be in possession of any shopping cart that has been removed from the parking area of a retail establishment with the intent to deprive the owner of the shopping cart the use of the cart.

(2) This section shall apply only when a shopping cart:

(A) Has a sign permanently affixed to it that identifies the owner of the cart or the retailer, or both;

(B) Notifies the public of the procedure to be utilized for authorized removal of the cart from the premises; 
(C) Notifies the public that the unauthorized removal of the cart from the premises or parking area of the retail establishment, or the unauthorized possession of the cart, is unlawful; and

(D) Lists a telephone number or address for returning carts removed from the premises or parking area to the owner or retailer.

(3) Any person who violates any provision of this section is guilty of a misdemeanor.

(Ord. 4153, 2014.)

\section{Pasco Municipal Code 9.34.065 Shopping Cart Theft.}

\section{Washington Ordinance Chart Methodology}

HRAP researchers catalogued every municipal jurisdiction surveyed in the 2010 Census - a total of 72 cities. The total surveyed population represents $53 \%$ of Washington State's total population. ${ }^{139}$ Two additional cities were included solely for their regional locations in order to capture a geographical representation of the entire state. ${ }^{140}$ The resulting chart allowed researchers to spot trends in the enactment of these ordinances.

All catalogued municipalities keep an online database of their municipal codes, but only some of these online databases had an integrated search function. To account for this, HRAP researchers created two separate surveying methods. First, for those databases with search functions, researchers searched for the following keywords: sleeping, sleep, camping, camp, sitting, lying, lodge, vehicle, loiter, loitering, loafing, vagrancy, obstruction, trespass, storage, bathing, urination, urinate, defecation, defecate, scavenging, begging, aggressive, panhandling, solicitation, and food. ${ }^{141}$ The effectiveness of database search functions varied considerably. ${ }^{142}$ In some instances, the database did not have a search function, so HRAP researchers resorted to browsing through the code manually. ${ }^{143}$ To ensure the reliability of both methods, researchers chose four municipalities with search functions and separately used both the search and browse methods, which ultimately generated the same results.

Upon finding a criminalization ordinance, researchers placed it into a category on the live-links chart. The live-links chart is divided by city and behavioral category, with every cited

\footnotetext{
${ }^{139} 2010$ Census data available at http://data.spokesman.com/census/2010/washington/cities/. The Census included only those cities with a population exceeding 10,000. Census Population Districts were not covered by researchers as they are creations of the census bureau and do not function in any way as a municipality.

${ }^{140}$ Omak to cover north-central Washington and Colville to cover the northeast region of Washington.

${ }^{141}$ These terms represent the kinds of conduct most likely targeted in homeless criminalization ordinances.

${ }^{142}$ Unsophisticated search functions would pull codes utilizing only the exact wording searched (for instance, a search for "urinating" would not reveal results for urination, urinate, or urinates). More sophisticated search functions pulled results by identifying the root word and pulling up any iterations of that root in the code. Identifying the sophistication of a given search function required searching for the root word, and then searching for common iterations of that search word, and noting the differences in the results. For those unsophisticated functions, researchers were forced to search both root words and all their possible iterations to ensure proper coverage.

${ }^{143}$ While admittedly more time consuming that using a search function, researchers found it helpful to pay close attention to code sections that commonly harbored criminalizing ordinances. For instance, chapters entitled "Health and Safety" or "Public Peace, Morals, and Welfare" frequently contained ordinances criminalizing obstruction, begging, and other behaviors. The "Park Code" also had anti-camping ordinances in nearly all jurisdictions.
} 
ordinance hyperlinked directly to the ordinance at issue. ${ }^{144}$ In addition to hyperlinking, each ordinance is indexed with at least the chapter and section titles to provide context for readers. Researchers identified the broad category of behavior a certain ordinance prohibited and then placed the ordinance into the chart under the specified category. ${ }^{145}$ In several instances, municipalities enacted two or more separate ordinances prohibiting the same category of conduct. In these situations, researchers placed the additional ordinances in subsequent rows under the same column. Similarly, municipalities would occasionally criminalize multiple categories of behavior in a single ordinance. In these cases, the offending ordinance was indexed under each category of prohibited behavior. Researchers included an "other" category to note ordinances that criminalized some behavior that appeared to disproportionality target the homeless population, but that did not fit neatly into a defined category. ${ }^{146}$ Before finalizing the live-links chart, researchers jointly reviewed all inputs and approved or denied their inclusion to further ensure reliability.

\section{Scope of Methodology}

While the researchers' methodology was effective, it is not without limitations. Primarily, there is no way to ensure $100 \%$ coverage of all criminalization ordinances. Any further analysis of the results should note that cities may well have additional ordinances lurking in their codes. Several factors contribute to this fact: (1) database lag time; (2) limited HRAP resources; (3) the potential for cities to creatively manipulate ordinance language to effectuate criminalization without explicitly claiming to do so - or at the least claiming to do so using traditional terminology; and finally (4) the presence of overlapping or compound ordinances.

There is a very real risk that ordinances may have been enacted or amended but not included in online databases. In one instance, researchers became aware of that exact scenario as Arlington passed an ordinance that was not reflected in the online database. Unfortunately, there is little researchers can do to protect against this issue. Occasionally, as was the case in Arlington, an ordinance may become popular due to local media attention; thus, it is worthwhile to stay connected in the local community and to run news searches for potential stories as the catalogue is filled in.

Another issue that presented a limitation was the resources of HRAP researchers. If there were additional researchers on this particular project, the live-links chart likely would have reflected all 275 municipalities. However, researchers observed the beginnings of diminishing returns on their investment as smaller cities tended to have far fewer ordinances than larger cities.

\footnotetext{
${ }^{144}$ Where direct hyperlinking to the ordinance was unavailable, researchers were forced to link to the municipality's general code page. In very few instances, a municipality elected only to publish the code in PDF format, in which cases the PDF is hyperlinked.

${ }^{145}$ In the event an ordinance used ambiguous language to effectuate a common criminalization, researchers conferred and, based upon the surrounding ordinances and perceived enacting intent, jointly decided whether to include the ordinance. An example would be ordinances criminalizing "offends the senses" which would be included depending on the ordinance's context. If the ordinance targeted businesses or owners of land, then it was excluded. If the ordinance was embedded among other personal conduct regulations, it was generally included.

${ }^{146}$ For instance, several jurisdictions outlawed possession of a shopping cart outside of a shopping center, which is a behavior not explicitly covered by any category in the chart but that researchers still felt was necessary to include.
} 
In those jurisdictions that allowed researchers to utilize a search function instead of the browsing method, there is a chance that some new and innovative ordinances criminalizing homeless conduct were missed. ${ }^{147}$ This concern is partially assuaged by the uniformity of results achieved when researchers independently browsed and searched four municipalities, demonstrating that this issue did not arise once in those four cities. The conclusion is that the problem, while certainly present, appears in relatively rare instances.

\section{Enforcement Data Methodology}

On August 6, 2014, HRAP researchers submitted the first round of public records requests to the cities of Auburn, Bellingham, Burien, Pasco, Seattle, Spokane, and Vancouver pursuant to the Washington Public Records Act (RCW $\$ 42.56$ et seq.). ${ }^{148}$ These cities were chosen from the originally surveyed 25 cities $^{149}$ because they appeared to criminalize the broadest range of behaviors. Seattle did not fall within this category, but instead was included due to being the largest city in the state. Burien was included a month later primarily because of the passage of Chapter 9.125 of the municipal code: a "trespassing ordinance" that allowed individuals to be banished from public spaces on account of body odor. ${ }^{150}$

HRAP researchers requested the following information from each city regarding the specific criminalization ordinances for that municipality:

1) The total number of citations issued under each ordinance for a five year period (January 1, 2009, through December 31, 2013);

2) The total number of citations that were issued to people who are homeless/transient, broken down by ordinance;

3) How many of the citations were resolved and how many were outstanding;

4) The consequent fines that result from any citation issued pursuant to the ordinances;

5) The total number of people who spent time in custody as a result of the citations;

6) The duration of time people spent in custody as a result of the citations;

7) The number of citations that led to the issuance of a warrant, and how many people were brought to the station and/or sent to jail pursuant to the warrant;

\footnotetext{
${ }^{147}$ For instance, researchers found a statute employing the term "protractedly lounge" to effectively criminalize lying down or sleeping. This term was not in our original methodology, but was found because it was embedded in an ordinance that also criminalized camping in public parks.

${ }^{148}$ Occasionally, the cities would refer researchers to the local municipal court or county jail for the data responsive to our requests. New requests were forwarded accordingly.

${ }^{149}$ Researchers initially conducted their study on the top 25 most populous cities in Washington and then subsequently expanded the study to 73 . The public records requests were sent after cataloging 25 cities but before expanding to 73 .

${ }^{150}$ The ordinance garnered widespread criticism for being both too harsh and too arbitrary. A more thorough discussion of the history surrounding this ordinance may be found in Part III.B.5.
} 
8) Whether there are consequent fines or additional charges resulting from a failure to appear for these citations.

As the data came in, researchers categorized the numbers of citations by the type of prohibited conduct. Doing so allowed researchers to view the data in a way allowing for comparison analysis despite differences in ordinance language between cities. This method functioned well with the exception of Spokane due to the overwhelming number of overlapping ordinances in that jurisdiction.

After receiving the initial data on citations from a particular city, HRAP researchers next sent an additional request seeking a broad range of demographic data. ${ }^{151}$ Researchers requested information regarding the cost per day to keep individuals in police custody, as well as the average "booking cost" for citations issued under an identified ordinance. Additionally, researchers asked for data relating to 15 demographic points including ethnicity, gender, and disability. ${ }^{152}$

One crucial piece of data was particularly difficult to obtain: the number of homeless individuals in each municipality. Although the One Night Count provides homeless populations for both Seattle and Auburn, no data could be found for other cities. ${ }^{153}$ The One Night Count is useful for advocates to educate the public and raise awareness regarding unsheltered homelessness. In addition, lawmakers can use the count as a comparison from one year to the next. Due to the practical constraints, however, the numbers underrepresent the actual number of homeless individuals in those cities. ${ }^{154}$ Notably, the most recent One Night Count did find an increase in the Seattle homeless population by $22 \%$ and an increase in Auburn's homeless population by $36 \%{ }^{155}$

\section{Researching Your Jurisdiction}

While this research is the most expansive to date, the methods used to obtain the data and perform the analysis are not unique to Washington State. This section encourages the replication

\footnotetext{
${ }^{151}$ See infra Appendix I-B.

${ }^{152}$ Complete list of demographic questions include: age, gender, ethnicity, disability (physical or mental health), citizenship, immigration status, veteran status, substance abuse, and identity as homosexual/bisexual/transgender. Researchers also inquired as to whether the defendants were receiving mental health services, had retained an attorney, or had retained a public defender.

${ }^{153}$ The One Night Count sends volunteers out to perform a point-in-time count of homeless individuals in shelters, with transitional housing providers, and on the street. The 2014 findings revealed 2,303 homeless individuals in Seattle and 97 homeless individuals in Auburn. Seattle/King County Coalition on Homelessness, 2014 Street Count Results, http://www.homelessinfo.org/what_we_do/one_night_count/2014_results.php (last visited Dec. 4, 2014).

${ }^{154}$ For instance, in California, early proponents of the One Night Count faced backlash even from homeless advocacy groups that feared the artificially low numbers would stifle funding and hinder policy advocacy efforts. Faye Fiore, Down for the Count: Critics of First Census of Homeless Say the Tally Destined to Be Low, L.A. TIMES (Mar. 18, 1990), available at http://articles.latimes.com/1990-03-18/news/hl-768_1_homeless-person. A spokesman for the Sacramento Homeless Organizing Committee estimated that the count was likely to find only 15-20\% of the homeless. Frank Clifford, Census Begins With the Nation's Homeless Count: 15,000 Fan Out For Monumental Overnight Task. Many Meet Difficulties. Incomplete Tally is Expected., L.A. TIMES (Mar. 21, 1990), available at http://articles.latimes.com/1990-03-21/news/mn-728_1_census-taker.

${ }^{155}$ Konopasek, supra note 52.
} 
of the same or similar studies in jurisdictions across the country. The section is split into two parts: first, a summary of the fundamental methodologies expressed throughout the article and combining them into a single easy to read guide; and second, a guide to expanding research beyond this study.

\section{A. Replicating Research in Your Jurisdiction}

Ideally, any research would be done by two or more researchers who can provide constant peer review toward the others' work. The first step in beginning a similar study is to cultivate a catalogue of offending ordinances by city and category. ${ }^{156}$ Second, choose which cities you would like to survey.

City selection can be based on population counts, which are then supplemented by other cities to provide geographical representation. The benefit of surveying populous cities is that they have census data. This data can be very useful in assessing trends and can also suggest areas for future research.

Third, having chosen the cities, new researchers should find the municipal code online and employ either the search or browse method to identify offending ordinances depending on the sophistication of the database. Researchers should review the identified ordinances together so that they may agree whether the ordinance disproportionately criminalizes conduct of necessary, life-sustaining activities. ${ }^{157}$ As researchers continue to go through the ordinance combing process, they should continually reevaluate the effectiveness of their search terms and vary them accordingly. ${ }^{158}$ Cultivating a live-links chart was helpful for quick reference throughout the project and is highly encouraged for other jurisdictions. The final step in the ordinance-gathering process is to make note of overlapping or compound ordinances, which researchers here have identified as problematic.

After identifying offending ordinances, the next step is to gain access to the enforcement data for those ordinances in key jurisdictions. ${ }^{159}$ Drawing from the public records request included here in the appendix, researchers should identify the public records officer for each jurisdiction. From this point on, the methods will have to be fluidly changed depending on the jurisdiction. Some jurisdictions will be helpful, while others will throw up cost prohibitive measures that deter the ultimate disclosure of the enforcement data. Researchers should expect to serve requests upon both the cities themselves as well as the municipal courts within the jurisdiction. The exact city agency will vary by municipality, but common agencies were city records offices and offices of the city attorney. Upon receiving, reviewing, and indexing the material germane to the core research questions of the project, analyze the data and draw whatever conclusions stand out.

\footnotetext{
${ }^{156}$ For a full discussion of the methodology used to cultivate the ordinance chart, please see Appendix part III.

${ }^{157}$ This peer review process was invaluable. While many ordinances clearly targeted conduct by the visibly poor, several ordinances were more vague or "on the line." While no method will ever be infallible, peer review and consensus allowed researchers to confidently retain only those that truly criminalized homelessness.

${ }^{158}$ It could very well be that the words and phrases employed in a different jurisdiction's criminalization ordinances are completely different from those employed in Washington jurisdictions.

${ }^{159}$ What those key jurisdictions is entirely up to the discretion of researchers who, at this point, are far more knowledgeable about the criminalization patterns in their jurisdiction than any other entity.
} 


\section{B. Expanding Research in Your Jurisdiction}

HRAP researchers were aware of resources available in other jurisdictions that were not available in Washington State, listed below. New researchers should check to see if the following resources do exist and, if they do, utilize them to their fullest. This is not meant to be an exhaustive list, so researchers must think outside the box when generating leads on knowledgeable individuals.

Several jurisdictions have homeless courts, which may provide a wealth of expertise and additional information not available to HRAP researchers. Non-governmental agencies, watchdog, and advocacy groups are generally willing to lend a helping hand to. If new researchers are administering surveys to homeless individuals, these groups become especially useful in connecting researchers to homeless communities. In a different vein, it may be worthwhile to consider qualitative data collection techniques such as interviewing enforcement personnel to get a more complete sense of how municipal ordinances may translate into enforcement. Ultimately, researchers should look to gain any additional information to help them understand the scope, purpose, and prevalence of criminalization ordinances, the assumptions behind them, and the enforcement strategies that follow in their wake. 


\section{Bibliography}

About Auburn, CITY OF AUBURN, http://www.auburnwa.gov/about.htm (last visited Dec. 4, 2014).

Katherine Beckett \& Steve Herbert, Banished: The New Social Control in Urban AMERICA (2009).

About Bellingham, CITY OF BELLINGHAM, http://www.cob.org/visiting/about.aspx (last visited Dec. 4, 2014).

Statement from the Burien City Manager Regarding its Trespass Ordinance, CITY OF BURIEN, http://burienwa.gov/DocumentCenter/View/5174 (last visited Apr. 1, 2015).

Frank Clifford, Census Begins With the Nation's Homeless Count: 15,000 Fan Out For Monumental Overnight Task. Many Meet Difficulties. Incomplete Tally is Expected., L.A. TIMES (Mar. 21, 1990), available at http://articles.latimes.com/1990-03-21/news/mn-728_1_censustaker.

Seattle/King County Coalition on Homelessness, 2014 Street Count Results, http://www.homelessinfo.org/what_we_do/one_night_count/2014_results.php (last visited Dec. 4, 2014).

Josh Farley, Bremerton Council Passes Panhandling Ordinance, KITSAP Sun (Nov. 6, 2014), http://www.kitsapsun.com/news/local-news/panhandling_vote_110714_21089784.

Faye Fiore, Down for the Count: Critics of First Census of Homeless Say the Tally Destined to Be Low, L.A. TIMES (Mar. 18, 1990), available at http://articles.latimes.com/1990-03-18/news/hl768_1_homeless-person.

Spokane, WA Metropolitan Statistical Area, FORBES, http://www.forbes.com/places/wa/spokane/ (last visited Mar. 31, 2015).

Deborah Horne, New Ordinance Allows Police to Ban Smelly People from City Buildings, KIRO 7 (Sept. 15, 2014), http://www.kirotv.com/news/news/new-ordinance-allows-police-ban-smellypeople-city/nhNK8/.

Josh Howard \& David Tran, Seattle University Homeless Rights Advocacy Project, AT WHAT Cost: The Minimum Cost of CRiminalizing Homelessness in SEATTLE \& SPOKANE (Sara Rankin ed., 2015).

King County 2010-2014 Consolidated Housing \& Development Program, 2009 Needs Assessment 11 (2009), available at www.kingcounty.gov/ /media/socialServices/housing/documents/2010_12_Consol_Plan_Appen d_A.ashx?la=en. 
KIRO 7 Eyewitness News, Burien's Trespass Ordinance to Address Disturbances in Public Spaces, KIROTV.COM (Aug. 23, 2014), http://www.kirotv.com/news/news/buriens-trespassordinance-address-disturbances-pu/ng74s/.

Michael Konopasek, King Co. Homeless Population up by More Than 20 Percent, KING 5 NEws (Feb. 4, 2015), http://www.king5.com/story/news/local/seattle/2015/01/23/king-countyhomeless-count/22210763/.

Spokane Police Clarify Sit and Lie Ordinance, 590 KQNT, http://www.590kqnt.com/articles/northwest-news-119088/spokane-police-clarify-sit-and-lie12810881/ (last visited Mar. 11, 2015).

Ian Lovett, When Home Has No Place to Park, THE New YORK TIMES (Oct. 3, 2010), available at http://www.nytimes.com/2010/10/04/us/04rv.html?_r=1.

Kaya Lurie \& Breanne Schuster, Seattle University Homeless Rights Advocacy Project, DisCRIMINATION AT THE MARGINS: THE INTERSECTIONALITY OF HOMELESSNESS AND OTHER MARGINALIZED GROUPS (Sara Rankin ed., 2015).

Scott MacDonald \& Justin Olson, Seattle University Homeless Rights Advocacy Project, WASHington CRiminaliZATION ORDinAnCE DATA (Sara Rankin ed., 2015).

The National Law Center on Homelessness \& Poverty, From Wrongs To Rights: The CASE For HOMELESS BILl OF Rights LEgislation (2014), available at http://nlchp.org/documents/Wrongs_to_Rights_HBOR.

Javier Ortiz \& Matthew Dick, Seattle University Homeless Rights Advocacy Project, THE Wrong Side OF History: A COMPARISON OF MODERN \& HistoricAl CRIMINALIZATION LAWS (Sara Rankin ed., 2015).

History and Highlights of Pasco, CITY OF PASCO, http://www.pasco-wa.gov/428/History-andHighlights-of-Pasco (last visited Mar. 31, 2014).

Levi Pulkkinen, Income Inequality: Which Washington City is Worst?, SEATTLE PoSTINTELLIGENCER, (Nov. 7, 2012), http://www.seattlepi.com/local/article/Income-inequalityWhich-Washington-city-is-worst-4004464.php\#photo-3682135.

Sara K. Rankin, A Homeless Bill of Rights (Revolution), 45 SETON HALl L. REV. 383 (2015), available at http://ssrn.com/abstract=2376488.

Kipp Robertson, Advocates Still Raising Stink Over Burien Law, Say it Targets Homeless, MYNORTHWEST.COM (Feb. 24, 2015), http://mynorthwest.com/11/2715929/Advocates-stillraising-stink-over-Burien-law-say-it-targets-homeless. 
Jennifer Romich, Poverty, Income Inequality Increase in Washington State, UWTODAY (Sept. 18, 2014), http://www.washington.edu/news/2014/09/18/poverty-income-inequality-increase-inwashington-state/.

John Ryan, After 10-Year Plan, Why Does Seattle Have More Homeless Than Ever?, KUOW.ORG (Mar. 3, 2015), http://kuow.org/post/after-10-year-plan-why-does-seattle-havemore-homeless-ever.

City of Seattle, Full Council of 3/30/15, SeATTLECHANNEL.ORG (Mar. 30, 2015), http://www.seattlechannel.org/mayor-and-council/city-council/full-council?videoid=x53504.

Letter from Jennifer Shaw to Lucy Krakowiak and the Burien City Council (Oct. 6, 2014), available at https://aclu-wa.org/news/aclu-urges-burien-repeal-unconstitutional-law-targetinghomeless.

U.C. Berkeley School of Law Policy Advocacy Clinic, California's New Vagrancy Laws: The Growing Enactment and Enforcement of Anti-Homeless Laws in the Golden State (2015).

U.S. Department of Commerce, State \& County QuickFacts, UniTED STATES CEnsus BuREAU, http://quickfacts.census.gov/qfd/states/53000.html (last visited Mar. 11, 2015).

Financial \& Management Services, Comprehensive Annual Financial Report at 186, CITY OF VANCOUVER, available at http://www.cityofvancouver.us/sites/default/files/fileattachments/financial_and_management_ser vices/page/1060/cityofvancouver2012cafr.pdf.

Community \& Economic Development, Destination Downtown, CiTY OF VANCOUver, http://www.cityofvancouver.us/ced/page/destination-downtown (last visited Mar. 31, 2015).

National Civil Rights Outreach Fact Sheet, W. Reg'L AdvocACy ProjeCt (April 5, 2013), available at http://wraphome.org/images/stories/pdffolder/NationalCivilRightsFactSheetMarch2013.pdf. 